Revista de Estudios Histórico-Jurídicos

[Sección derechos de la antigüedad salvo el romano]

XXXVIII (Valparaíso, Chile, 2016)

[pp. 47 - 75]

\title{
EL SIGNIFICADO HISTÓRICO-JURÍDICO DE LAS LEYES TEODORICIANAS
}

[The historical and juridical meaning of the Teodoricians Laws]

\author{
Eduardo ANDRADEs Rivas* \\ Universidad del Desarrollo, Chile
}

\begin{abstract}
RESUMEN
Este trabajo estudia las fuentes de conocimiento, contenido, significado e importancia de las denominadas Leyes Teodoricianas, las primeras leyes escritas que los visigodos dictaron para regular la repartición de las tierras entre ellos y los romanos, como consecuencia del asentamiento visigodo en los territorios del Imperio Romano de occidente. Se hace especial énfasis en la importancia de dichas leyes en relación a la vigencia territorial del derecho visigodo.

Palabras Clave

Leyes Teodoricianas - Teodorico - Sidonio Apolinar - Visigodos - Sortes góticas - Tercia romanorum - Código de Eurico - leyes territoriales - Líber Iudiciorum.
\end{abstract}

Abstract

This paper examines the sources of knowledge, content, meaning and importance of so-called Theodoricians Laws, the first written laws to the Visigoths issued to regulate the distribution of land between them and the Romans, as a result of the Visigoth settlement in the territories of the Western Roman Empire. Special emphasis on the importance of these laws regarding the territorial validity of Visigothic law is made.

\section{KeYwords}

Teodorician laws - Theodoric Sidonius Apollinaris - Visighots - Gothic sorts - Roman Tertias - Code of Euric territorial laws - Lex Visigothorum.

RECIBIDO el 14 de marzo y ACEPTADO el 14 de junio de 2016

* Magíster en Humanidades con mención en Historia Clásica, Universidad del Desarrollo. Profesor Titular de Historia del Derecho en la Facultad de Derecho de la Universidad del Desarrollo. Dirección postal: Ainavillo 456, $5^{\circ}$ piso, Concepción, Chile. Correo electrónico: eandrade@udd.cl. 


\section{INTRODUCCIÓN}

Las llamadas Leyes Teodoricianas no suelen motivar mayor atención en los estudios jurídicos, aparte de una brevísima referencia a los inicios de la legislación gótica antes de explicar el código de Eurico y la legislación goda posterior. Pero el estado de la cuestión pareciera indicar que deberíamos destinarles un mayor análisis. Nuestros conocimientos sobre su periodo histórico, mediados del siglo $\mathrm{V}$, ha aumentado en forma considerable en los últimos años. A los estudios que, sobre el particular, ha publicado el profesor Orlandis ${ }^{1}$, debemos sumar los análisis sobre historia eclesiástica visigoda ${ }^{2}$, los militares, los económicos y los culturales en general ${ }^{3}$. Además publicaciones de divulgación, como las de Cebrián ${ }^{4}$. En el ámbito anglosajón son incontables los estudios sobre este periodo perteneciente a la denominada "antigüedad tardía". Igualmente, biografías sobre los personajes históricos de la época van abriendo paso a una mayor comprensión dicho tiempo ${ }^{6}$.

${ }^{1}$ Ver Orlandis, José, Historia del Reino Visigodo Español (Madrid, Editorial Rialp, 2006).

2 Ver Castellanos, Santiago, Los godos y la cruz. Recaredo y la unidad de Spania (Madrid, Alianza Editorial, 2007); Orlandis, José y Ramos-Lisson, Domingo, Historia de los concilios de la España romana y visigoda (1981, traducción castellana de ellos mismos, Pamplona, EUNSA, 1986); Saranyana, Josep-Ignasi y Tejero, Eloy (editores), Hispania Christiana, estudios en honor del prof. Dr. José Orlandis Rovira en su septuagésimo aniversario (Pamplona, EUNSA, 1988).

3 Ver ARCE, Javier, Bárbaros y romanos en Hispania (400-507 A.D.) (2005, primera reimpresión de la segunda edición, Madrid, Marcial Pons Historia, 2011); ARCE, Javier, Esperando a los árabes. Los visigodos en Hispania (507-711) (Madrid, Marcial Pons Historia, 2011); y CASTEllanos, Santiago, En el final de Roma. (ca. 455-480) (Madrid, Marcial Pons Historia, 2013).

${ }^{4}$ Véase Cebrián, Juan Antonio, La aventura de los Godos (Madrid, Editorial la Esfera de los Libros, 2002).

5 Ver, entre otras, Heather, Peter, La caída del Imperio Romano² (2005, traducción castellana de Tomás Fernández Aúz y Beatriz Eguibar, Barcelona, Editorial Crítica, 2008); FERRIL, Arther, La caída del Imperio Romano, las causas militares ${ }^{2}$ (1986, traducción castellana de Pilar González Bermejo, México, Editorial EDAF, 1998), 304 pp., RosEN, William, El fin del Imperio Romano, la primera gran peste de la era global (2007, traducción castellana de Marita Osés, Barcelona, Paidós, 2008); y Jones, Terry y EREIRA, Alan, Roma y los bárbaros, una historia alternativa (2006, traducción castellana de Tomás Fernández Aúz y Beatriz Eguibar, Barcelona, Editorial Crítica, 2008).

${ }^{6}$ Aparte de los textos jurídicos que examinamos, las noticias más directas sobre las Leyes Teodoricianas se las debemos a San Sidonio Apolinar, noble galorromano y obispo de ClermontFerrand, cuyas cartas han llegado hasta nosotros. Entre otros muchos documentos relativos al santo, la colección más completa de sus obras se encuentra en los Monumenta Germaniae Historica, Auctores Antiquissimi, vol. VIII. En versión latina y francesa existe la de GrEGOIRE, J. F. y Collombet F. L., Oeuvres de C. Sollius Apollinaris Sidonius, Traduites en Francais avec le Texte en Regard et des Notes (París, Broché, 1836), I y II. Su biografía más completa, en dos tomos, editada en el siglo XIX es la del padre Chaix. Ver ChaIX DE LaVArène, Louis Antoine C., Saint Sidoine Apollinaire et son siécle (Clermont-Ferrand, Ferdinand Thibaud Imprimeur Libraire, 1866). Hay versión digitalizada de esta biografía en el sitio electrónico https://archive. org/details/saintsidoineapo00lavagoog (consulta 11 febrero 2015). Igualmente debe citarse la biografía que compuso el Rev. Padre Alban Butler, inserta en su Vidas de los Santos, ver Butler, Alban, Vidas de los Santos de Butler (1954, traducción castellana de Wilfredo Guinea, S. J., México, Orozco y Berra, 1965), III, pp. 384ss. En inglés una documentada síntesis de su vida puede encontrarse en Stevens, C. E., Sidonius Apollinaris and his Age (Oxford, Clarendon 
Pero no por ello podemos afirmar que resulta sencillo abordar el estudio de la época en que surgen las fuentes legislativas que motivan el presente trabajo. Se trata de un tiempo del que tenemos fuentes y testimonios incompletos, parciales y muchas veces contradictorios. Recordemos que hasta hace poco era habitual referirse a este tiempo como "la edad oscura"

\section{EL CONTEXTO Y LAS FUENTES HISTÓRICAS}

Entre 270 y 273 el emperador Aureliano (214-270-275), consciente de que el Imperio Romano ya no podía mantener sus fronteras más allá del Danubio, abandonó la provincia de Dacia. Ello facilitó que los pueblos germanos ocuparan la zona, destacando los tervingios o vesi o godos del oeste, que entraron en contacto con Roma hacia fines del siglo III, celebrando acuerdos como foederati. Su entrada en el imperio se verificó en el siglo siguiente, a partir de 370, en forma pacífica, como fruto de una convivencia de 100 años. Sin embargo, una vez asentados en la ribera sur del Danubio se produjeron frecuentes choques. Estos conflictos estallaron finalmente en un enfrentamiento que se saldó con la Batalla de Adrianópolis (378), la victoria de los godos, liderados por Fritigerno (¿?-380) y la derrota y muerte del emperador Valente (328-364-378) en la batalla.

Más tarde, tras nuevos intentos de pacificación y hostilidades, Alarico I (370395-410) El Grande, saqueó Roma (410), primer asalto a la capital en casi ocho siglos. Los visigodos siguieron su trayecto rumbo a Sicilia, pero la muerte de Alarico les hizo retornar y dejar Italia rumbo a Hispania. Un sobrino de Alarico, Ataúlfo (¿372?-410-415) fue elegido rey. Y sería este mismo Ataúlfo quien tomaría como rehén a la hermana del emperador Honorio (384-395-423), Gala Placidia (388-450). Tras los desórdenes que siguieron al saqueo de Roma, Ataúlfo y su pueblo se radicaron en Barcino (Barcelona), es decir en la provincia Tarraconensis de la diócesis de Hispania. Ambas partes intentaron un acercamiento. A ello ayudó el matrimonio entre Ataúlfo y Gala en 414 y la gran influencia que ésta ejerció sobre su marido ${ }^{8}$. El rey godo fue asesinado en 415 , por orden de uno de

Press, 1933), 224 pp. La edición completa de las cartas de San Sidonio se encuentra en lengua inglesa en Dalton, O. M. The letters of Sidonius (Oxford, The Clarendon Press, 1915), I-II. Hay versión digitalizada en el sitio web Tertulian.org, en http://www.tertullian.org/fathers/ \#sidonius_apollinaris (consulta 11 febrero 2016). La versión íntegra y original en latín de sus obras, se encuentra en el sitio web The Latin Library, disponible en http://www.thelatinlibrary. com/sidonius.html (consulta 23 marzo 2015). Para múltiples materiales sobre Sidonio, véase el sitio web http://www.sidoniusapollinaris.nl (consulta 8 septiembre 2015). Finalmente, un análisis de San Sidonio como orador, político, polemista y obispo lo encontramos en el estudio del profesor Santiago Castellanos sobre el fin del Imperio Romano occidental, ver CastelLANOS, Santiago, En el final de Roma, cit. (n. 3), pp. 115ss.

7 Ciertamente no por un supuesto "oscurantismo", sino a la falta de fuentes que nos proporcionen algo de información. Se trata de un tiempo en donde la tradición oral casi reemplaza al escrito y por ello debemos tenerlo siempre presente.

${ }^{8}$ Orosio, Paulo, Historiarum adversum paganos, versión latina original digitalizada en el sitio electrónico The Latin Library, disponible en http://www.thelatinlibrary.com/orosius.html (consulta 13 marzo 2015), VII, 42, 5-6. "se inprimis ardenter inhiasse, ut oblitterato Romano nomine Romanum omne solum Gothorum imperium et faceret et uocaret essetque, ut uulgariter loquar, 
sus enemigos, Sigerico (¿?-415-415), quien le sucedió 9 . Tras un breve reinado de una semana, éste fue también asesinado y su sucesor fue Walia (¿?-415-418), hermano de Ataúlfo. Sería el nuevo rey quien reiniciaría contactos con Roma. Fracasado un intento por trasladarse con todo su pueblo a África, Walia negoció con el Imperio. En 416 Roma firmó un foedus o acuerdo de asistencia militar con los godos ${ }^{10}$, que incluyó la restitución de Gala Placidia. Asimismo el Imperio debía entregar 600 mil modios de trigo a fin de alimentar a los godos, que carecían de recursos debido al bloqueo romano del comercio marítimo. En virtud del acuerdo los visigodos se radicaron en los territorios romanos con la obligación de auxiliar a las autoridades imperiales en caso de necesidad. Dicho de otra forma, los visigodos recibieron las tierras del sur de las Galias (la Aquitania II) ${ }^{11}$ y una creciente influencia sobre Hispania, con la obligación de defender tales territorios de la invasión de otros invasores.

Cuando Walia fue nombrado magister militum de Hispania por el general Constancio (360-421), aquél asumió rápidamente sus obligaciones militares, que le imponían al ejército visigodo el acabar con los demás bárbaros asentados en su zona, especialmente en Hispania; los alanos, vándalos y suevos que habían entrado en la península en $409^{12}$. Tras dos años de campañas, Walia fue llamado

Gothia quod Romania fuisset et fieret nunc Athaulfus quod quondam Caesar Augustus, 6 at ubi multa experientia probauisset neque Gothos ullo modo parere legibus posse propter effrenatam barbariem neque reipublicae interdici leges oportere, sine quibus respublica non est respublica, elegisse saltim, ut gloriam sibi de restituendo in integrum augendoque Romano nomine Gothorum uiribus quaereret habereturque apud posteros Romanae restitutionis auctor, postquam esse non potuerat immutator." Traduccion española: "Al principio, decía, yo deseaba ardientemente que el nombre romano fuese borrado y que todos los territorios romanos se convirtiesen en un imperio de los godos; yo ansiaba que Romania llegase a ser Godia y Ataúlfo fuese César Augusto. Pero he aprendido, gracias a una experiencia mayor que la libertina ciencia, que los godos no admitirán nunca su obediencia a las leyes, y sin leyes una república no es república. He elegido el camino más prudente de aspirar a la gloria de restaurar e incrementar el nombre romano con el vigor godo; y espero pasar a la posteridad como el iniciador de una restauración romana, ya que es imposible para mi cambiar la forma del Imperio." Esta última ha sido tomada de Ferril, Arther, cit. (n. 5), p. 193. Respecto de las actitudes filorromanas de Ataúlfo, ver ARCE, Javier, Bárbaros, cit. (n. 3), p. 78. Sobre la influencia de Gala Placidia sobre su marido ver GESINO, Marta, El libro séptimo de las historias contra los paganos de Paulo Orosio, en Anales de Historia Antigua y Medieval, 1959-1960 (Buenos Aires, 1961) p. 50.

9 Entre otras acusaciones los asesinos reprocharon a Ataúlfo su acercamiento con Roma, de lo que Olimpiodoro nos da luz al señalar que la romanitas del rey llegó al punto de contraer matrimonio con Gala Placidia vestido de general romano. Ver DíAZ, Pablo C., Rey y Poder en la monarquía visigoda, en Iberia 1 (Logroño, 1998) pp. 179ss. Sobre la cercanía a Roma de Ataúlfo y Teodorico se pronuncia el prof. Arce, ver ARCE, Javier, Esperando a, cit. (n. 3), p. 62.

${ }^{10}$ Ver Marín Riveros, José, Textos históricos. Del Imperio Romano hasta el siglo VIII (Santiago, RIL Editores, 2003), pp. 29ss.

11 Ver Jones, Terry y Ereira, Alan, cit. (n. 4), p. 203.

12 Nos dice Orosio en su Historiarum adversus paganum, Libro VII, 40, 9-10: "9 igitur Honoriaci inbuti praeda et inlecti abundantia, quo magis scelus inpunitum foret atque ipsi sceleri plus liceret, prodita Pyrenaei custodia claustrisque patefactis cunctas gentes, quae per Gallias uagabantur, Hispaniarum prouinciis inmittunt isdemque ipsi adiunguntur: 10 ubi actis aliquamdiu magnis cruentisque discursibus, post graues rerum atque hominum uastationes, de quibus ipsos quoque modo paenitet, habita sorte et distributa usque ad nunc possessione consistunt.". Traducción castellana: "9 de esta manera, los "honoriacos", embotados y a con el saqueo y seducidos por la abundancia, para que 
nuevamente a las Galias, luego de completar la destrucción de vándalos y alanos y haber reducido a los suevos a la antigua provincia de Gallaecia $^{13}$. Renovado el foedus con Roma en 418, Walia logró asentar su autoridad sobre el nuevo territorio. Los dominios de los godos se centraban en la provincia Aquitania $I I^{14}$, aunque desde el mismo Walia hasta Alarico II (¿̨-484-507), los reyes visigodos intentaron ampliar su territorio hacia el norte de las Galias y hacia el mediterráneo e Hispania ${ }^{15}$. La capital del reino fue fijada en Tolosa, y los godos lograron controlar la Septimania, que quedaría igualmente bajo su dominio ${ }^{16}$.

Así, los visigodos no eran un pueblo recién ingresado en el Imperio Romano. Esta es una de las grandes singularidades de los visigodos si los comparamos con los demás pueblos germánicos y/o asiáticos que más tarde entrarían en el Imperio. Los godos llevaban una larga convivencia con Roma, de casi medio siglo, por lo que se encontraban ya muy romanizados. Su nobleza hablaba latín e incluso el pueblo llano había desplazado las costumbres germanas por los hábitos latinos (dieta, vestiduras, actividad económica, comercial y agrícola) ${ }^{17}$. Por ello no resulta extraño que sus reyes hayan seguido la política legislativa de los emperadores, como ya imitaban a Roma en muchas otras manifestaciones culturales, y dictaran leyes escritas en latín para resolver los problemas que acaecían en su reino.

En el mismo año 418 de la renovación del foedus con Roma, fallecía el rey

su crimen fuese más impune y más grande, abandonando la defensa del Pirineo y dejando expeditos los desfiladeros, dejaron entrar en las provincias hispánicas a todas las gentes que pululaban por las Galias y se unieron a ellos; 10 y alli, realizando de vez en cuando grandes y cruentas correrías, después de terribles pérdidas de hombres y bienes -de lo que de alguna manera ellos mismos se arrepienten-una vez distribuidas por sorteo las tierras, permanecen establecidos como dueños de ellas." La traducción anterior es de SAYAS ABENGOCHEA, Juan José, Historia antigua de la península ibérica (Madrid, Ediciones UNED, 2014), p. 540.

${ }^{13}$ IsIdoro, de Sevilla San, Historia Gothorum, 21, 1. "Aera et anno quo supra, Walia Sigerico succedens, tribus annis regnum tenuit, belli causa princeps a Gothis effectus, sed ad pacem divina providentia ordinatus, mox enim cum regnare coepit, foedus cum imperatore Honorio pepigit, Placidiam sororem ejus, quae a Gothis Romae capta fuerat, ei honorifice reddidit, promittens imperatori propter rempublicam omne certamen implendum. Itaque ad Hispanias per Constantium patricium evocatus, Romani nominis causa caedes magnas Barbaris intulit.". Traducción castellana: "En la era y año indicados [a. 416], Valia, sucediendo a Sigerico, tuvo el reino durante tres años, hecho principe de los godos con motivo de la guerra, aunque ordenado para la paz por la providencia divina. Pues luego que comenzó a reinar, celebró un tratado con el emperador Honorio. Su hermana Placidia, que habia sido capturada por los godos en Roma, se la devolvió honrosamente, prometiendo al Emperador tomar parte en toda batalla por la República. De esta manera fue llamado a España por el patricio Constancio."

${ }^{14}$ Ibíd., 22. "[...] Confecto igitur Walia bello Hispaniae, relictis Hispaniis, Gallias repetit; dataque ei ab imperatore ob meritum victoriae secunda Aquitania cum quibusdam civitatibus confinium provinciarum usque ad Oceanum". Traducción castellana: "Terminada, pues, la guerra de España, valia volvió a las Galias, donde el Emperador le dió en premio de la victoria la Aquitania segunda con ciertas ciudades en los confines de las provincias hasta el Atlántico".

15 "En Hispania, de 416 a 418, Walia se dedicó con furia a la conquista de otros bárbaros. El resultado fue una devastación del pais, que fue saqueado por ejércitos de ambos bandos". Ver FERRIL, Arther, cit. (n. 5), p. 199.

${ }^{16}$ Ver ARCE, Javier, Bárbaros, cit. (n. 3), pp. 107ss.

17 Ver Le Goff, Jacques, La civilización del occidente medieval (1982, traducción castellana de Godofredo González, Barcelona, Ediciones Paidós Ibérica. S.A., 1999), pp. 27ss. 
Walia y los nobles elegían a su sobrino, Teodorico I (¿̨-418-451) o Teodoredo, yerno de Alarico I, como nuevo monarca, quien reinó largos años. Especialmente importantes fueron sus pactos con la Roma de Valentiniano III (419-424-455), aunque su relación de confianza fue con el general Aecio (396-454). No obstante que algunos han sostenido, con escasa base histórica, que los godos no tenían ningún "control sobre la población aquitana, en medio de la cual habían sido instalados" 18 , lo cierto es que la autoridad de Teodorico resultó efectiva tanto respecto de su pueblo como respecto de sus súbditos romanos.

Su época fue también la de la descomposición definitiva de Roma como potencia. Sin la intervención visigoda en apoyo de los romanos, en la Batalla de los Campos Cataláunicos (451), el general Aecio, no habría podido obtener su gran victoria contra las hordas de Atila (395-453). De hecho, el rey Teodorico I falleció combatiendo y las tropas visigodas representaron la principal columna del ejército romano, que de tal no tenía más que el nombre. Su hijo Turismundo (¿-451-453), fue elegido por los soldados visigodos como nuevo rey, in armis insonantibus. Pero su reinado, distanciado de Aecio y de Roma, duró escaso tiempo y tras un atentado cometido por sus propios hermanos Teodorico (¿?-453-466),

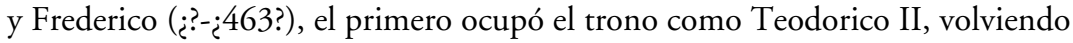
al pacto con Roma, lo que le permitió ampliar sus territorios e incorporar a más poblaciones galo e hispanorromanas a su control. Teodorico II terminó de consolidar el llamado reino Tolosano. De hecho, Teodorico II fue uno de los apoyos (o tal vez el principal impulsor) de Eparquio Avito (385-455-457) en su ascensión al trono imperial. A ello contribuyó la formación de Teodorico II como verdadero patricio romano ${ }^{19}$.

Fue aquí donde surgió la necesidad de repartir las tierras en las que ahora se asentaban los godos como nueva minoría gobernante. Debe recordarse que la diferencia entre el número de la población visigoda y la galorromana era enorme. Mientras las estimaciones más optimistas nos hablan de una población visigoda total de entre 60.000 a 80.000 almas, la población galorromana superaba ampliamente los cuatro millones. Los godos, empero, no eran trashumantes, ansiaban radicarse en nuevas tierras y lograr prosperar y crecer en ellas. Desde su ingreso en el Imperio habían anhelado un territorio propio. Por su reducido número, el deseo de tierras de los visigodos no supuso el desposeer de sus fundos y fincas a toda la población romana. Se piensa que solo afectó a las grandes propiedades, las más cercanas a algunas de las ciudades ocupadas por los godos y benefició no a todos los germanos sino a las capas más altas. Fue un eficiente sistema de repartición, que generó conflictos menores.

18 Ver Thompson, E. A., Los godos en España (1969, traducción castellana de Javier Faci, Madrid, Alianza Editorial Historia, 2007), p. 14. Sostiene que los godos "vivían bajo sus propias leyes y jefes y conservaban sus propias costumbres, religión y lengua”. Afirmación matizable, sin perjuicio de reconocer que los godos de la época (418) ya tenían leyes. Estas leyes eran precisamente aplicables a la totalidad de la población sin que pueda circunscribírselas al ámbito de aplicación que pretende darles el autor.

${ }^{19}$ Ver Díaz, Pablo C., cit. (n. 8), p. 182 y Castellanos, Javier, En el final de Roma, cit. (n. 3), pp. 115ss. 
Esta solución fue ideada por los propios visigodos, pues en la legislación del Código Teodosiano y en las novelas post-teodosianas que conservamos no hay norma que resuelva el conflicto de repartición de las tierras. Son leyes que complementan al derecho romano vulgar y aportan respuestas originales al problema del asentamiento de un pueblo nuevo sobre los territorios imperiales. Parece ser que el origen de la solución, se vincula con la antigua noción romana de hospitalitas, especialmente recogida en una constitución imperial de Arcadio (377-395-408) y Honorio de 398, por la cual se dividía una finca en tres porciones similares y se la repartía entre el propietario original y el huésped. Como ya hemos indicado, el asentamiento de los visigodos en las Galias pudo efectuarse, en un primer momento, teniendo como sustento la institución de hospitalitas ${ }^{20}$ entre godos y el Imperio.

El Código Teodosiano (438) regulaba la hospitalitas en virtud de la citada constitución imperial, disponiendo: "Impp. arcadius et honorius aa. hosio magistro officiorum. In qualibet vel nos ipsi urbe fuerimus vel ii qui nobis militant commorentur, omni tam mensorum quam etiam hospitum iniquitate summota duas dominus propriae domus, tertia hospiti deputata, eatenus intrepidus ac securus possideat portiones, ut in tres domu divisa partes primam eligendi dominus habeat facultatem, secundam hospes quam voluerit exequatur, tertia domino relinquenda..." 21.

De acuerdo al precepto citado los recién llegados se establecieron con sus familias entre la población romana. Los godos, denominados hospes tenían derecho a reclamar un tercio de las propiedades en donde se radicaban. El propietario romano, llamado possesor en virtud del pacto de hospitalitas conservaba los dos tercios restantes. Esta era la regla general, con una excepción en caso de que el hospes fuera un inlustris, en cuyo caso la propiedad se dividía por mitades ${ }^{22}$. Sin embargo el sistema comentado no logró resolver el problema. Al contrario de los típicos foederati del pasado, Roma aceptó a los godos junto a todas sus familias. Es decir, los hospes no eran solo unos soldados a sueldo, sino toda la nación goda ${ }^{23}$. Por ello la cesión de las tierras debió abarcar partes adicionales para cultivarlas y trabajarlas en beneficio del total de la nueva población. Esta nueva forma de repartir las tierras sería el sustrato de hecho para la dictación de las Leyes Teodoricianas. La fracción de las tierras o fincas entregadas a los godos se denominaron sortes y

${ }^{20}$ Ver SAITTA, Armando, Guía crítica de la historia medieval (1981, primera reimpresión, traducción castellana de Stella Mastrangelo, México, Fondo de cultura económica, 1996), p. 61.

${ }^{21}$ Ver Código Teodosiano, 7,8,5. Traducción castellana “Los emperadores Arcadio y Honorio a Osio, Maestro de los oficios: En cualquier ciudad en que Nos mismo estuviéremos o en la que residieren los que nos sirven en la milicia, para quitar toda iniquidad tanto de los medidores como de los huéspedes, el dueño posea sin miedo y con seguridad dos partes de su propia casa, y se entregue la tercera al huésped. De este modo que dividida en tres partes la casa, el dueño tenga la facultad de elegir la primera, el huésped elija la segunda, la que quiera, y la tercera quede para el dueño." (6 de febrero de 398).

${ }^{22}$ Ver, D’Ors, Álvaro, El Código de Eurico, Edición, Palingenesia, Indices² (Madrid, Boletín Oficial del Estado, 2014), p. 173.

${ }^{23}$ Ver Alvarado Planas, Javier, Montes Salguero, Jorge J., Pérez Márcos, Regina María, SÁnchez González, María Dolores del Mar, Practicum, textos comentados de Historia del Derecho y de las Instituciones adaptados al programa de la Uned (Madrid, Editorial Universitaria Ramón Areces, 2005), p. 78. 
los dueños romanos originales fueron llamados con consortes $^{24}$. Así, repartición de las tierras fue de los hechos más importantes del reino tolosano ${ }^{25}$.

Ya dijimos que los testimonios históricos de la época de las Leyes Teodoricianas son escasos y fragmentarios. Con todo, contamos con algunos de importancia ${ }^{26}$, dentro de los cuales, aparte de la obra de Sidonio Apolinar, los más completos resultan ser los Fragmentos de Olympiodoro de Tebas ${ }^{27}$, los VII Libros de historia contra los paganos de Paulo Orosio ${ }^{28}$ y la Crónica o Chronicón de Hidacio, Obispo de Chaves, estos dos últimos hispanorromanos originarios del norte de la Península y cuyas obras abarcan el periodo que va desde el fin del siglo IV hasta $468^{29}$.

Olympiodoro de Tebas (378-425) nos dejó la noticia de la entrada de los visigodos en Hispania, de su asentamiento en Barcino, del matrimonio entre Ataúlfo y Gala Placidia ${ }^{30}$ y del asesinato de Ataúlfo por orden de Sigerico ${ }^{31}$. Destaca la

${ }^{24}$ Ver De las Heras y NúNEEZ, María de los Ángeles, Las instituciones visigodas, disponible en http://www.vallenajerilla.com/berceo/heras/institucionesvisigodas.htm (consulta 10 febrero 2015).

25 Ver Thompson, E. A., Los godos en, cit. (n. 18), p. 15.

26 Una lista debidamente actualizada de las fuentes puede consultarse en ARCE, Javier, Bárbaros, cit. (n. 3), pp. 21ss.

27 Olympiodoro, originario de Tebas, Egipto, fue un intelectual y diplomático al servicio del Imperio Romano. Su embajada más conocida fue ante los hunos entre 412 y 413 . De su Historia de Roma en 22 volúmenes (dedicada a Teodosio II) disponemos de 40 fragmentos recogidos por Focio. Habría ido desde los años 407 a 425. Sus relatos de la invasión bárbara de Hispania en el 409 y del asentamiento visigodo en Barcino, sirven para comprender el deseo de los bárbaros por radicarse. Su obra inspiró la de Zósimo. Ver Matthews, J. F., Olympiodorus of Thebes and the history of the west (A.D. 407-425), en The Journal of Roman Studies, 60 (London, 1970), pp. 79-97. Y GIROTTI, Beatrice, Spunti per la continuità tra Olimpiodoro di Tebe e Prisco di Panion, en Historia: Zeitschrift für Alte Geschichte, 54 (Erfurt, 2005) 3, pp. 305-358.

${ }_{28}$ Ver Orosio, Paulo, cit. (n. 7). Hay versión impresa en español, ver Orosıo, Paulo, Historias contra los paganos (Zaragoza, Prensas Universitarias de Zaragoza, 2008).

29 Paulo Orosio fue un sacerdote, teólogo y escritor romano de origen hispano, nacido en Bracara Augusta, Gallaecia. Miembro de la nobleza hispanorromana, por el Mediterráneo, conoció a San Agustín, de quien fue amigo. Llegó hasta Jerusalén en donde conoció a San Jerónimo y a Alejandría de Egipto. Su Historia contra los paganos le fue encargada por San Agustín como complemento de su Ciudad de Dios. Al parecer fue escrita entre 416 y 417 . Ver Torres Rodríguez, Casimiro, Paulo Orosio. Su vida y sus obras (La Coruña, Fundación Pedro Barrie de la Maza Conde de Fenosa, 1985).

Por su parte Hidacio, sacerdote, obispo de Chaves, fue diplomático e historiador, pertenecía también a la aristocracia provincial de Gallaecia. Nació en una familia acomodada, por lo que desde joven se dedicó a los estudios y a viajar. También visitó Tierra Santa y allí hizo amistad con San Jerónimo, cuya obra continuó en la propia, siendo su Crónica una prolongación de la obra del santo de Estridón. Ver ArCE, Javier, Bárbaros, it. (n. 3), pp. 21 ss. Asimismo, ver Idatius Aquaeflaviensis Episcopus, Chronicum versión latina disponible en http://www. thelatinlibrary.com/hydatiuschronicon.html (consulta 8 febrero 2015). Existe edición bilingüe latina española del Episcopologio Asturicense en: http://bibliotecadigital. jcyl.es/i18n/ catalogo imagenes/grupo.cmd?path=1006419\&interno $=S \&$ posicion $=262 \&$ presentacion $=$ pa gina (consulta 11 febrero 2015).

${ }^{30}$ Ver Thompson, E. A., Olympiodorus of Thebes, en The Classical Quarterly 38 (Cambridge, 1944) $1 / 2$, pp. 43-52.

31 Ver Jiménez Garnica, Ana María, Nuevas Gentes, Nuevo Imperio: Los Godos y Occidente en el Siglo $V$ (Madrid, Editorial UNED, 2010), pp. 74ss. 
relación de Ataúlfo con la familia imperial. Y nos da noticias de cómo se veía en Roma a los visigodos y de la incapacidad del Imperio para imponerse frente a ellos.

Paulo Orosio (¿383?-¿417?) contemporáneo del anterior, nos relata el saqueo de Roma por Alarico I y el posterior periplo de los visigodos hasta su primer asentamiento en Barcino. Narra la entrada de los pueblos bárbaros en Hispania. Orosio no denostó a los bárbaros, a pesar del saqueo de Roma. El autor usó una estructura apologética y providencialista al describir los cuatro imperios antiguos frente al imperio romano cristiano. Valiéndose de cronologías similares analizó a las viejas Babilonia, la Roma clásica pagana, los macedonios y a Cartago, a los que describió de forma pesimista. Pese a la crisis que se vivía en su tiempo Orosio confiaba en el futuro de Roma que, por su carácter cristiano, lograría la conversión de los bárbaros. De interés en Orosio es su descripción de la crisis de las ciudades y de la fuga de los ciudadanos romanos a los campos. Ello nos sirve para explicar el proceso de asentamiento de los bárbaros en territorios imperiales que, en la práctica, estaban en gran medida despoblados.

De Hidacio (¿400?- ¿469?), obispo de Aquae Flaviae (Chaves), conservamos su famoso Chronicón, en el que describe desde la creación del mundo hasta sus días. La descripción de su época abarca desde 379 a 468. Al contrario de la obra de Orosio, la de Hidacio tiene un marcado acento pesimista. Presentó a los bárbaros, especialmente a los suevos, de los que fue su historiador casi exclusivo, como un pueblo de ladrones, depredadores, violentos y asesinos. Solo veía en ellos un factor negativo y de decadencia de la cultura. Tal vez la razón de fondo con respecto a tal apreciación radica en sus problemas personales con los líderes suevos. Hidacio perteneció a la aristocracia romana de Gallaecia, que fue la principal perjudicada por los bárbaros, que sufrió sus depredaciones y la confiscación de sus tierras. Por su dignidad episcopal y su preparación intelectual, Hidacio no pudo escapar al papel de líder y adversario de los invasores. Ello condicionó su obra. Hidacio nos da, aunque en forma secundaria, informaciones sobre los visigodos y su asentamiento en el Imperio ${ }^{32}$.

\section{El testimonio de San Sidonio Apollinar}

Gayo Solio Apolinar Sidonio, o San Sidonio Apolinar (431-489) fue uno de los últimos patricios romanos, originario de las Galias. Militar, orador, político, intelectual, jurista y finalmente activo obispo cristiano. Nacido en Lugdunum (Lyon), Galia, fue miembro de una de las principales familias de la aristocracia galorromana de su tiempo. Los Apolinares formaban parte del núcleo gobernante de las Galias, lo que le daba su singularidad al régimen romano en dichas provincias, donde la autoridad estaba fuertemente sujeta y cooptada por los optimates provinciales. El padre y el abuelo de Sidonio desempeñaron el cargo de Prefectos del Pretorio. Por su entorno familiar, Sidonio tuvo la mejor formación intelectual.

32 Sobre el reparto de tierras tenemos una referencia en el Chronicón de Hidacio. Ver ARCE, Javier, Bárbaros, cit. (n. 3), p. 25. 
Destacó en la oratoria y en la poesía ${ }^{33}$. De su producción literaria nos han llegado numerosas de sus Epístolas y Cartas ${ }^{34}$.

En lo político fue un líder que enfrentó las crisis de su tiempo. Sin embargo, de carácter pacífico, sus escritos no abundan en la descalificación de sus adversarios. Una de las pocas excepciones es el testimonio que nos dejó acerca de las Leyes Teodoricianas.

Contrajo matrimonio con Papianila, quien le dio cuatro hijos. Su mujer era hija de Eparquio Avito, noble galorromano de origen senatorial, Magister Militum de las Galias bajo el breve reinado de Petronio Máximo (¿396?-455-455) y más tarde emperador romano. Conviene detenerse en este hecho, que demuestra la influencia de los visigodos en la política imperial. Mientras Petronio era asesinado en Roma, Avito se encontraba en la corte de Teodorico II. Éste vio la oportunidad de situar en el trono imperial a quien le diera garantías. Presionó a los miembros de la nobleza galorromana para que proclamaran augusto a Avito, lo que aconteció el 9 de julio de $455^{35}$. Avito entró en Roma en donde fue reconocido por el Senado, con la reticencia de los senadores itálicos que lo veían con recelo por ser provincial (crítica injusta pues Avito descendía de una familia itálica). Su yerno Sidonio le acompañó y pronunció un panegírico en su honor ${ }^{36}$. Pero el reinado de Avito no fue feliz. Por una parte no era apreciado por los habitantes de la Urbe y por otra debió enfrentar la guerra contra los vándalos. No obstante su victoria en Panonia, los vándalos bloquearon Roma impidiendo la llegada de alimentos. Para pagar a su guardia debió fundir las estatuas de los héroes del pasado, lo que destruyó su escaso apoyo popular. Tras desórdenes el emperador huyó a Arlés. No logró apoyo de Teodorico II por lo que reclutó por sí mismo un ejército para reconquistar Italia, pero fue vencido en Piacenza y hecho prisionero por Ricímero (405-472), militar de origen bárbaro, hombre fuerte del Imperio junto al romano Mayoriano (420-457-461). Volvió a huir y murió en circunstancias poco claras.

La política seguía de cerca a Sidonio. El nuevo emperador fue Mayoriano También Sidonio pronunció el panegírico ${ }^{37}$. En él reclamó a Mayoriano que emprendiera la conquista del África vándala, el gran enemigo de Roma en ese

33 Ver Butler, Alban, cit. (n. 6), pp. 384ss.

${ }^{34}$ Como ya se dijo tenemos una abundante colección de sus escritos en el sitio web The Latin Library, disponible en http://www.thelatinlibrary.com/sidonius.html (consulta 23 abril 2015).

35 IsIDORo, de Sevilla San, cit. (n. 7), 31. "Aera CDXCI, anno II imperii Marciani, Theudericus, post fraternam necem, in regnum succedens, [... qui pro eo quod imperatori Avito sumendi imperialis fastigii cum Gallis auxilium praebuisset, ab Aquitania in Hispaniam, cum ingenti multitudine exercitus, et cum licentia ejusdem Aviti imperatoris [...]". Traducción castellana: "En la era 491 [a. 453], en el segundo año del reinado de Marciano, Teodorico [II], después de la muerte de su hermano le sucedió en el trono... y porque habia ayudado al emperador Avito a alcanzar la supremacia imperial con ayuda de los galos, de la Aquitania pasó a España con multitud de ejército y con licencia del mismo emperador Avito."

${ }^{36}$ Ver el texto original latino, de gran interés por la erudición y elocuencia del autor, en The Latin Library, disponible en el sitio http://www.thelatinlibrary.com/sidoniuscarmina.html (consulta 12 febrero 2016).

37 Ibíd. 
tiempo ${ }^{38}$. Pero el reinado del militar romano no fue más venturoso que el anterior. Su frustrada campaña naval contra los vándalos le restó el apoyo de Ricimero. Fue obligado a abandonar el trono por sus propios soldados. Murió poco después, al parecer envenenado por orden de Ricimero, en 461. Tras un breve reinado de interludio de Libio Severo (420-461-465) el emperador oriental León I el tracio (401-457-474) proclamó como emperador a Antemio (420-467-472). Nuevamente Sidonio pronunció su panegírico ante el Senado, el 1 de enero de $468^{39}$. Antemio, le nombró Prefecto de la Urbe. Sin embargo, la incapacidad del emperador para gobernar movió a Sidonio a renunciar y volver a las Galias.

Nuestro autor fue uno de esos hombres que comprendió a tiempo que el Imperio estaba condenado. Y como otros de su clase, determinó pasar del cursus honorum imperial, que se extinguía, a la jerarquía de la Iglesia ${ }^{40}$. Fue preconizado obispo de Arvenum (más tarde Clermont-Ferrand), por aclamación popular y de los obispos de Auvernia. En su nueva calidad de obispo debió enfrentar la expansión del reino visigodo de Eurico (415-466-484) en territorio galo ${ }^{41}$. Usó de sus numerosos bienes para dar alimento y techo a miles de refugiados de la guerra romano-visigoda. Fue auxiliado por su cuñado Ecdicio Avito (420-¿475?) hijo del exemperador Avito $^{42}$. Cuando los visigodos de Eurico sitiaron Clermont, Sidonio exhortó a la población a resistir. Ecdicio fue encargado de la defensa. No obstante los visigodos se impusieron y Sidonio debió huir. Años más tarde retornó, no sin resistencia de parte de los nuevos señores. Falleció en una fecha que no conocemos, entre 479 y 489 . Fue elevado a los altares, más que por sus virtudes heroicas, por el positivo recuerdo que dejó entre los católicos de su diócesis a quienes defendió con todo su patrimonio personal ${ }^{43}$.

\section{La carta de San Sidonio Apolinar a Ecdicio.}

En sus escritos a sus cercanos, Sidonio solía dar noticias de los hechos que habían acontecido en la Galia y en el Imperio. Es lo que hace en una de sus misivas a su cuñado Ecdicio. La carta fue redactada en el contexto de la guerra entre los visigodos de Tolosa y los galorromanos que hacían lo posible por mantener a sus tierras libres de los germanos y regidas por el Imperio, aunque fuera nominalmente. En dicho conflicto hubo miembros de la aristocracia que, percibiendo que el fin del Imperio era inminente, cambiaron de lealtades, sirviendo a ambos bandos, según fuera apropiado a sus intereses. Y uno de ellos fue Seronato, al que Sidonio alude en su carta.

38 Ver Heather, Peter, cit. (n. 5), p. 504.

39 Ver Apolinar, Sidonio, Carmina III, The Latin Library, disponible en el sitio http:// www.thelatinlibrary.com/sidoniuscarmina.html (consulta 12 febrero 2016). Asimismo consultar Heather, Peter, cit. (n. 5), pp. 499ss.

${ }^{40}$ Un completo análisis del tema del paso de San Sidonio del orden político romano al eclesiástico puede consultarse CASTELlanos, Santiago, En el final de Roma, cit. (n. 3), pp. 229ss. y pp. 241 ss.

${ }^{41}$ Ver Butler, Alban, cit. (n. 5), pp. 384ss.

${ }^{42}$ Ecdicio fue importante en Roma. En 474 el emperador Julio Nepote (430-474-480) lo nombró patricio y magister militum.

${ }^{43}$ Ver Butler, Alban, cit. (n. 5), pp. 384ss. 
Las noticias que tenemos acerca de este personaje son escasas ${ }^{44}$. En todo caso sabemos que fue un funcionario de origen galorromano que usó su autoridad en beneficio de los visigodos ${ }^{45}$. San Sidonio, en un lenguaje que no es frecuente en él, lo acusa de ser "ipse Catilina saeculi nostri" ${ }^{46}$. Al parecer ejerció funciones judiciales como vicario de las 7 provincias o vicario del Prefecto del Pretorio de las Galias, en la porción libre que quedaba de la Aquitania I. Arbitrariamente alzó los impuestos y trabajó al servicio de Eurico, a quien sirvió hasta que el visigodo logró apoderarse de toda la Auvernia de San Sidonio hacia 469. Según nos dicen las mismas cartas, fue acusado por traición ante los tribunales romanos, aún subsistentes, y ejecutado en 471. No fue el único en actuar así; San Sidonio nos da noticia de Vicentius Arvandus (464-469), Prefecto del Pretorio quien, en connivencia con Eurico, alentó a los godos a ocupar las Galias, junto a los burgundios. Arvandus se comportó de forma parecida a Seronato, aunque no pagó sus abusos con la vida. Ello demuestra que las aristocracias de la Galia comenzaban a sentir que los godos, más que enemigos, se podían volver sus salvadores frente a los demás pueblos bárbaros que presionaban desde el norte ${ }^{47}$.

\section{El contenido de la carta.}

De la información y datos que contiene se desprende que la breve carta que nos interesa parece haber sido escrita bajo el reinado de Antemio entre 467 y $471^{48}$.

La sección que nos interesa, en donde San Sidonio alude a Seronato y a las Leyes Teodoricianas, es: Epístolas, libro II, Carta, 3 a Ecdicio: "exultans Gothis insultansque Romanis, inludens praefectis conludensque numerariis, leges Theodosianas calcans Theodoricianasque proponens veteres culpas, nova tributa perquirit" ${ }^{\prime 9}$.

Aunque parezca sorprendente este breve párrafo, no más largo que una oración compuesta, es el único testimonio histórico general que tenemos de la existencia de las Leyes Teodoricianas. Las fuentes restantes son indirectas o son las que se contienen en los cuerpos legales visigodos posteriores. San Sidonio denunció la traición que veía en Seronato, que siendo un magistrado romano se ponía al servicio de los visigodos, con los cuales existía una guerra abierta por el dominio

${ }^{44}$ Para un buen análisis sobre el personaje, su relación con San Sidonio Apolinar y las fuentes del periodo, ver Goffart, Walter A., Barbarians and Romans, A.D. 418-584: The Techniques of Accommodation (Chichester, Princeton University Press, 1980), pp. 246-248. Asimismo ver Mathisen Ralph W. y SivAn, Hagith S. Forging a new identity: The kingdom of Toulouse and the frontiers of visigothic Aquitania (418-507), FERREIRO, Alberto (ed.), The Visigoths: Studies in Culture and Society (Koninklijke, Brill, 1999), pp. 32ss. y Jones, A.H.M., MarTindale, J.R. y Morris, J. Prosopography of the Later Roman Empire (Cambridge, Cambridge University Press, 1971-1992) II, pp. 395ss.

45 Ver Castellanos, Santiago, En el final de Roma, cit. (n. 3), pp. 145ss.

46 Traducción castellana: "Ese Catilina de nuestro tiempo". Ver Apolinar, Sidonio, Epístolas, Libro II, 1,1 .

${ }^{47}$ Ver, D’Ors, Álvaro, El Código, cit. (n. 22), p. 5.

48 Apolinar, Sidonio, Epistolarum, II, 1.

49 Traducción castellana: "[Seronato, gobernador de Aquitania II] ensalza a los godos, insulta a los romanos, se burla de los prefectos y juzga con los recaudadores, pisotea las leyes teodosianas y aplica las teodoricianas, castiga viejas culpas y exige nuevos tributos." 
de las Galias y específicamente por el de la Auvernia, la patria de Sidonio. Pero la denuncia de San Sidonio no terminó allí, pues al cuestionamiento moral y político, unió una acusación de la mayor gravedad, pues hizo responsable a Seronato de dejar de aplicar el derecho romano vigente, esto es el Código Teodosiano, y aplicar en su reemplazo las leyes dictadas por los visigodos, a las que llamó T e o d o r i c i a n a s. En esta acusación existen dos elementos de interés:

El primero es que Seronato, un magistrado romano, a la sazón, vicario del Prefecto del Pretorio de las Galias, dejara de aplicar las leyes del Imperio. Ello demuestra la debilidad de la autoridad romana que ya no era capaz de imponer el derecho romano ni siquiera en los territorios que todavía nominalmente controlaba. El segundo y más interesante es que en reemplazo del derecho romano aplicara unas denominadas "Leyes Teodoricianas".

Hay aquí varios aspectos a considerar:

a) Antiguamente se discutió sobre la identidad del legislador de las Leyes Teodoricianas, sosteniendo que Eurico se llamó primero Teodorico, tomando luego el nombre por el que le conocemos y que en lengua germana habría significado "legislador o codificador eminente" ${ }^{50}$. También se ha dicho que la expresión Theodoricianas sería un simple error de copia y que habría cambiado el adjetivo original Euricianas ${ }^{51}$. Este supuesto error se explicaría por las semejanzas fonéticas entre ambos vocablos. Sin embargo, esta tesis ha sido descartada, otorgando plena fe al testimonio de San Sidonio al respecto ${ }^{52}$.

b) Si Teodorico I y II dictaron leyes, entonces ¿cómo explicar que San Isidoro de Sevilla, en su crónica sobre la historia del reino godo, sostenga que fue Eurico el primer legislador visigodo ${ }^{53} \mathrm{La}$ afirmación de San Isidoro debe matizarse, pues al contrario de San Sidonio, el santo de Sevilla escribió su historia más de doscientos años después de los hechos, mientras que el testimonio de San Sidonio es contemporáneo a los mismos. Por otro lado, se ha explicado esta aparente contradicción sosteniendo que Eurico dictó la primera compilación general de todo el derecho vigente, lo que no descarta que su padre y hermano mayor hayan dictado leyes parciales para la repartición de las tierras ${ }^{54}$. En fin, otros han sostenido que

${ }^{50}$ Ver Ortiz de Zárate, Ramón, Análisis histórico-crítico de la legislación española (Vitoria, Imprenta y litografía de Egaña y Cía., 1844), I, pp. 11 ss.

${ }^{51}$ Ver el discurso de Lardizábal en la edición de 1815 del Fuero Juzgo, LaRDizÁBAL Y Uribe, Manuel de, Fuero Juzgo por la Real Academia Española, 1815 (Madrid, Boletín Oficial del Estado, 2015), pp. VIIIss.

52 Sobre el estado de la polémica y su superación, ver UREÑa y SMENJAUd, Ramón, La legislación gótico-hispana (leges antiquiores-Liber Iudiciorum). Estudio crítico (Pamplona, Urgoiti Editores, 2003), pp. 135ss.

53 Ver Isidoro, de Sevilla San, Historia Gothorum, 35 "Sub hoc rege Gothi legum statuta in scriptis habere coeperunt, nam antea tantum moribus et consuetudine tenebantur.". Traducción castellana: "Bajo este rey (Eurico), los godos comenzaron a tener por escrito las instituciones de las leyes, pues antes se regían por las mores y por la costumbre”. Sobre el particular se pronuncia en apoyo de San Isidoro, De la Peña y Portillo, Dionisio, De la ley de los visigodos (Madrid, Imprenta de la Esperanza, 1858), pp. 10ss.

${ }^{54}$ Ver Morán Martín, Remedios, Materiales para un curso de Historia del Derecho español (Madrid, UNED, 2010), I, pp. 275ss. 
la afirmación de Isidoro se referiría a que Eurico fue el primero que dictó leyes como rey independiente de Roma, que cayó pocos antes de su Código ${ }^{55}$.

c) San Sidonio habla con claridad de le y e s, por lo que no puede asociarse esta afirmación con las costumbres germanas primitivas ${ }^{56}$. No, la palabra lex designa, en la mentalidad de un romano culto como Sidonio, a una norma escrita en el sentido romano de lo que llamamos legislación.

d) Dentro de las diversas formas de leyes que los romanos distinguían por su formalidad y propósito, es de suponer que se trataba de Edicta, es decir, normas de carácter general dictadas por el Emperador, o en este caso, los reyes visigodos como autoridades delegadas del Imperio ${ }^{57}$.

e) Los autores de las leyes tendrían que ser Teodorico I y su hijo Teodorico II. No tenemos referencias adicionales para saber qué es lo que habrían aportado cada uno a las Leyes Teodoricianas. Pero podemos suponer que siendo Teodorico I el primer rey que en la práctica tuvo control oficial sobre los territorios romanos en virtud del foedus de 418, habría sido él el que dictó las leyes de reparto de las tierras $^{58}$. Más aún recordando la gran influencia romana en su corte, a la que acudió Avito, quien habría convertido al rey al romanismo jurídico ${ }^{59}$. Por ello, Teodorico II sería el autor de unas leyes que habrían complementado las originales, y podría ser a tales leyes, hoy perdidas, a las que se refería en general San Sidonio ${ }^{60}$. Con todo, la cuestión dista de estar cerrada ${ }^{61}$.

f) No puede atribuirse directamente a los dos Teodoricos la redacción de las leyes que estudiamos, aun cuando Teodorico II tuvo gran interés en la legislación

55 Ver Escudero, José Antonio, Curso de Historia del Derecho, Fuentes e Instituciones político administrativas $^{2}$ (Madrid, Talleres de Gráficas Solana, 1995), p. 196.

${ }^{56}$ Ver Montiel, Isidro A., Cuadro Sinóptico del Código de Eurico, en El Derecho, Periódico de jurisprudencia y legislación, I (México, 1868) 5, p. 1.

57 Ver Gacto Fernández, Enrique, Alejandre García, Juan Antonio y García Marín, José María, Manual de Historia del Derecho (Temas y antología de textos) (Madrid, Editorial Dykinson, 2013), pp. 61-63.

58 Así lo dice el prof. Escudero en base al Código de Eurico, que alude a las leyes de Teodorico I, padre de Eurico: "Antiquos vero terminos sic stare iubemos sicut et bonae memoriae pater noster in alia lege praecepit". Traducción castellana: "Pero los antiguos linderos mandamos que estén tal como en otra ley mandó nuestro padre de buena memoria". Ver EsCUDERO, José Antonio, cit. (n. 55) pp. 196ss.

59 Ver D'Ors, Álvaro, El Código, cit. (n. 22), p. 6.

${ }^{60}$ Ver García-Gallo, Alfonso, El origen y la evolución del derecho, Manual de Historia del Derecho Español (Madrid, Artes Gráficas y Ediciones S.A., 1977), I, p. 57 y Alvarado Planas, Javier, et al, Manual de Historia del Derecho y de las Instituciones (Madrid, Editorial Sanz y Torres S. L., 2006), p. 172. En contrario F. Beyerle sostiene que siendo las Leyes Teodoricianas una modificación a la legislación teodosiana de la hospitalitas, lo que Teodorico II habría ordenado era un verdadero código que no alcanzó a promulgar y que sería la base del Código de Eurico. Ver Escudero, José Antonio, cit. (n. 55) p. 197. La profesora Madden afirma que las Leyes Teodoricianas serían de 469-471, obra de Teodorico II, pero ignora que el reinado de éste finalizó en 466, ver MADDEn, Marie Regina, Political theory and law in medieval Spain (Clark, The Lawbook Exchange Ltd., 2005), p. 31.

${ }^{61}$ Una versión sintética del estado de la cuestión puede consultarse en VALVERDE CASTRO, María R., Ideología, simbolismo y ejercicio del poder real en la monarquía visigoda; un proceso de cambio (Salamanca, Ediciones Universidad de Salamanca, 2000), pp. 70-72. 
de su reino ${ }^{62}$. Es más que probable que esta legislación, escrita en latín, haya sido redactada por romanos asesores de los reyes, como Flavio Magno de Narbona $(\dot{2} ?-475)^{63}$.

Todavía nos restan otras dos afirmaciones de San Sidonio, con las que concluye su denuncia a Seronato: "proponens veteres culpas, nova tributa perquirit" (castiga viejas culpas y exige nuevos tributos).

En relación a las culpas nos parece que se podría referir a que desató persecuciones contra sus enemigos, entre quienes se encontraba el propio San Sidonio. Así, podría haber reabierto causas ya falladas en contra de sus adversarios y/o haber lanzado amenazas de enjuiciar a los que se oponían a los visigodos. En suma, cualquiera que hayan sido sus acciones, San Sidonio nos informa de que hizo mal uso de las potestades judiciales penales que investía. Por su parte, los nuevos impuestos a los que se alude podrían ser muchos. Desde contribuciones especiales con motivo de las guerras o mayores tributos a los productos agrícolas, que eran casi los únicos generados en la zona, hasta multas y diversas prestaciones para recaudar mayores ingresos para hacienda imperial o incluso no es descartable que con esos fondos contribuyera al tesoro de los propios godos a quienes podría haber sobornado. Una posibilidad interesante, teniendo presente el contenido de las Leyes Teodoricianas, sería que Seronato hubiese alzado los impuestos territoriales que pagaban los consortes romanos por su tercia a fin de compensar la exención que tenían los visigodos respecto de sus sortes (2/3 del total) adjudicadas. Ello implica una doble violación de la legalidad, pues por una parte, en su calidad de magistrado, Seronato carecía de esa facultad y por la otra aplicaría a ciudadanos romanos una legislación extranjera, que resultaba explicable en los territorios gobernados por los godos, pero no en tierras del Imperio.

\section{LOS TEXTOS LEGALES, EVOLUCIÓN Y ANÁLISIS}

Veamos ahora las fuentes jurídicas visigodas en que se contienen las referencias a nuestras Leyes Teodoricianas. Desde la publicación de la obra de E. Th. Gaupp, el más antiguo estudio sobre la materia ${ }^{64}$, se ha tenido cierto acuerdo en que la

${ }^{62}$ "Todo esto muestra qué intensa relación existía entre una y otra zona.; cómo, si el poder de los reyes visigodos crecía en prestigio ante la población romana, la cultura romana habia dominado a los invasores. En estas circunstancias, es natural que existiera cierto paralelismo entre los actos normativos de uno y otro lado. Como todos los gobernadores provinciales, aunque para un ámbito mayor, el prefecto del pretorio, que no podia dar leyes, daba si edicta; el rey visigodo, en cambio, daba leyes, como son las de Teodorico que Seronato aplicaba abusivamente en zona todavía romana, probablemente de los dos Teodoricos I y II, de las cuales se conservan algunos vestigios en las mismas leyes de Eurico." Ver D’Ors, Álvaro, El Código, cit. (n. 22), p. 6.

${ }^{63}$ Así lo han sostenido D’Ors, Levy y Escudero. Sin embargo, subsiste el problema de la data de las leyes, pues Magno de Narbona fue miembro del Prefecto del Pretorio de las Galias tiempo después (458-459) del reinado de Teodorico I (418-451).

${ }^{64}$ Ver Gaupr, E. Th., Die Germanischen Ansiedlungen und Landttheilungen in den Provinzen des römischen Westreiches in ihrer völkerrechtlichen Eigenthümlichkeit und mit Rücksicht auf verwandte Erscneinungen der alten Welt und des späteren Mittelalters dargestellt (Breslau, 1844), pp. 394ss. 
legislación teodoriciana tuvo como punto de partida el asentamiento de los godos en las Galias en el siglo $\mathrm{V}$ y que nosotros hemos fijado en el reinado del primer Teodorico, en una fecha que debe ser cercana al $418^{65}$.

\section{En el Código de Eurico.}

El primer documento jurídico preservado, que incorporó una referencia directa a la legislación de los Teodoricos, fue el Codex Euricianus o Código de Eurico (476), quien fuera hijo y hermano de los anteriores. Pero no hay que olvidar que en el tiempo de Eurico el asentamiento de los godos en las Galias llevaba casi cincuenta años, por lo que lo que el Código hizo fue recoger una legislación referente a un sistema de reparto de tierras que estaba consolidado y que ya había rendido prácticamente todos sus frutos. En tal sentido se entiende que el texto de las Leyes Teodoricianas, recogido en el Código, se halle inserto dentro de un libro denominado "De divisionibus", que se extendía a otro tipo de divisiones o particiones de bienes. Tampoco contamos con una versión íntegra del Código de Eurico, pero gracias a los fragmentos transcritos en el Palimpsesto de París, podemos conocer las disposiciones que nos interesan. Más recientemente la palingenesia del Código publicada por el profesor D'Ors ha facilitado enormemente su acceso ${ }^{66}$.

¿Cómo operaba el mecanismo recogido? Era relativamente sencillo: se basaba en la división de las tierras en tres porciones similares. Se concedía al visigodo el derecho de escoger la primera. Enseguida el propietario romano escogía "la tercia" que le parecía mejor entre las dos restantes. Y la tercera parte final no escogida era igualmente asignada al visigodo. En la práctica lo que se hacía era conservar el mecanismo de la hospitalitas pero invirtiendo la repartición en beneficio de los godos. Así tenemos una legislación visigótica profundamente influida por el derecho romano. Las dos partes del godo se llamaron "sortes gothicae" y la del propietario original "tertia romanorum". Los germanos lograban un asentamiento en tierras amplias y fácilmente explotables y los terratenientes romanos no eran desposeídos de toda su propiedad sino que conservaban una porción valiosa. Este reparto no podía ser impugnado ni por los godos ni por los romanos para reclamar más de lo que les correspondía por aplicación de la fórmula indicada y así se evitaban las querellas interminables. La extensión que podemos dar a esta fórmula ha sido fuente de más controversias. Los autores del siglo XIX, entre los que podemos citar a Torres ${ }^{67}$ y Zeumer ${ }^{68}$, estimaron que la totalidad de las tierras fueron sometidas a esta forma de reparto, incluyendo a las propiedades urbanas, a las que se hizo extensivo el reparto. Pero a mediados del siglo XX, el profesor García Gallo demostró que el reparto solo afectó a los grandes propietarios de

65 Puede ser que los repartos antecedieran incluso a la misma Ley. El prof. Escudero afirma que el reparto se inició bajo el gobierno de Walia. Ver Escudero, José Antonio, cit. (n. 55), p. 177.

${ }^{66}$ Ver D’Ors, Álvaro, El Código, cit. (n. 22).

${ }^{67}$ Ver TORRes López, Manuel, Las invasiones y los reinos germánicos de España, en MENÉNDEZ Pidal, Ramón (ed.), Historia de España (Madrid, Espasa Calpe, 1954), III.

${ }^{68}$ Ver Zeumer, Karl, Historia de la legislación visigoda (Barcelona, Editorial Universidad de Barcelona, 1944). 
latifundios. La pequeña propiedad agrícola no fue objeto de particiones pues de haberlo sido no habría logrado rendir lo suficiente para mantener ni a galorromanos ni a godos ${ }^{69}$. Por lo demás existen algunos testimonios históricos que prueban que las reparticiones no afectaron a todos los propietarios por igual ${ }^{70}$.

Aunque se trate de una tesis, el profesor García-Gallo afirma que las zonas de repartición se dividieron en dos: las trabajadas directamente por sus dueños romanos (terra dominicata), y las que eran trabajadas por colonos y/o arrendatarios (terra indominicata). En las primeras el propietario era quien conservaba dos tercios cediendo el restante al visigodo, conservando la regla de la hospitalitas. En las segundas la fórmula operaba como se ha dicho. De esta manera el perjuicio que sufrían los propietarios romanos originales no era de tal entidad como para complicar las relaciones, pues las tierras indominicatas pasaban hereditariamente entre colonos, los que le pagaban una muy pequeña cantidad como tributo al dueño original. Era este derecho lo único que se perdía. No obstante carecer de información que confirme esta explicación, resulta atendible si consideramos que la fórmula de reparto, evitó mayores conflictos entre ambos grupos sociales ${ }^{71}$. Finalmente hemos de reiterar el carácter minoritario de estas cesiones. No fue todo el pueblo visigodo el beneficiado con el reparto sino la clase dirigente ${ }^{72}$.

Volvamos ahora al texto legal que recoge la fórmula, el Código de Eurico (dictado en 476) $)^{73}$ :

Codex Euricianus: CCLXXVII “(1) Sortes Gothicas et tertiam romanorum quae intra L annis non fuerint revocate nullo modo repetantur. (3) Antiquos vero terminos sic stare iubemus sicut et bonae memoriae pater noster in alia lege praecepit"74.

En la primera parte del precepto se recoge la fórmula que hemos explicado, la distribución de las tierras entre godos y galorromanos en razón de dos tercios para

${ }^{69}$ Esta es la tesis que hoy comparte la inmensa mayoría de los especialistas. Ver THOMPSON, E. A. Los Godos, cit. (n. 18), pp. 160ss. Y GarCía-GaLlo, Alfonso, Notas sobre el reparto de tierras entre visigodos y romanos, en Hispania 4 (Madrid, 1941) pp. 40-63.

${ }^{70}$ El prof. Castellanos nos recuerda el caso de Paulino de Pella (376-460?), quien poseyendo tierras en Aquitania no fue desposeído de ellas sino hasta muy avanzada su vida. Ver CastelLANOs, Santiago, En el final de Roma, cit. (n. 3), pp. 45 ss.

71 Ver García-Gallo, Alfonso, Notas sobre, cit. (n. 69).

72 Ver Escudero, José Antonio, cit. (n. 55), p. 179.

73 Otra fecha posible es 481. Aunque ajeno a este estudio, sobre la fecha de dictación del Liber puede verse un artículo del profesor García González, que aborda el tema de la autoría de la disposición del 277 del Código. En él sostiene que la norma tuvo que ser obra de un solo legislador, y que tenía por fin establecer un plazo de prescripción especial de 50 años (el común era de 30) para permitir a los perjudicados con los primeros repartos (ocurridos más de 30 años antes) demandar su derecho y así evitar las situaciones inestables derivadas de la repartición. Según su cálculo resultaría que de ser Eurico el autor del precepto, el Código no podría ser posterior al 468. Pero acepta la posibilidad de que la norma completa del 277 fuere obra de Teodorico II (o sea una Ley Teodoriciana propiamente tal), en cuyo caso no se podría datar el Código en base al 277. Ver García GonzÁlez, Juan, Consideraciones sobre la fecha del Código de Eurico, en $A H D E$., 26 (Madrid, 1956), pp. 701-706.

${ }^{74}$ Código de Eurico. Traducción castellana: "“(1) Las parcelas godas y la tercia de los romanos que no fueron reclamadas en un plazo de cincuenta años, no puedan en modo alguno ser reclamadas. (3) Ordenamos mantener los linderos tal y como ya mandó en otra ley nuestro padre de digna memoria." 
los godos y uno para el propietario galorromano original. Agrega la disposición una cláusula de claro origen euriciano, al disponer que transcurridos 50 años desde el reparto no podría formularse ninguna alegación contra la división practicada.

Un complemento de lo afirmado se encuentra en la Ley Antiqua 10, I, 16 del Líber, en donde se ordenaba a los jueces que restituyeran a los propietarios romanos las tercias que hubiesen sido indebidamente ocupadas por los visigodos, salvo que hubieren pasado 50 años, con lo que se produce una concordancia perfecta con lo que sostenía el 277, 1 del Código de Eurico ${ }^{75}$.

La afirmación contenida en el párrafo 3, en donde Eurico alude a la legislación dictada por su padre, probaría, según don Álvaro d'Ors, que el sistema de las Leyes Teodoricianas habría estado ya consolidado a la época de la dictación del Código $^{76}$. Concordamos plenamente con esta tesis.

No es mucho más lo que podemos afirmar sobre el contenido del libro " $D e$ divisionibus" en que se encuentra inserto el precepto que hemos transcrito ${ }^{77}$. La disposición anterior (276) conservada parcialmente se refiere a la fijación de los límites entre las porciones de tierra de los consortes romanos y godos. Establecía un mecanismo para determinarlos y prohibía que se practicaran sin permiso de la otra parte y la intervención de un tercero. Disponía sanciones en caso de infringir la prohibición ${ }^{78}$. Por su parte el propio apartado 277 , que contiene las disposiciones que hemos comentado, las integra dentro de otras normas que se refieren a la prescripción: en el número 2 se aborda la prohibición de reducir a la servidumbre a los siervos fugitivos transcurridos más de 50 años. El número 4 consagra un principio general por el cual los juicios pendientes por más de 30 años no pueden seguir siendo reclamados. El número 5 impone una multa de una libra de oro al que intentare proseguir el juicio pendiente pasado el plazo

75 Liber Iudiciorum, 10, I, 16. "Iudices singularum civitatum, vilici adque prepositi tertias Romanorum ab illis qui occupatas tenent auferant et Romanis sua exactione sine aliqua dilatione restituant, ut nihil fisco debeat deperire; si tatem eos quinquaginta annorum numerus aut tempus non excluserit". Traducción castellana: "Que los jueces de cada una de las ciudades, los administradores y los prepósitos tomen, a aquellos que las tengan ocupadas, las terceras partes de los romanos y que con la fuerza de su autoridad las restituyan a aquellos sin dilación, de manera que el fisco no deba perder nada; eso, asimismo, si no lo impidiere el hecho de haber transcurrido cincuenta años."

76 Ver D’Ors, Álvaro, cit. (n. 22), p. 174.

77 De hecho corresponde al primer fragmento subsistente en el Palimpsesto de París.

78 Código de Eurico, CCLXXVI. "3 [...] Si vero fundorum termini in tertiis quas habent Romani fuerint, tunc Gothi ingrediantur in loco hospitum et ducant terminum ubi fuerat ostensus. 4. Tunc iudex, quos certiores agnoverit, facias eos sacramenta praebere quod terminum sine ulla fraude monstraverint. 5. Nullus novum terminum sino consorte partis alterius aut sine in spectore constituat. 6. Quod si forsitam liber hoc fecerit, damnum pervasoris excipiat quod legibus continetur. 7. Si vero hoc servus admiserit domino nesciente, CC flagella publice extensus accipiat, et nullum ex hoc praeiudicium domino conparetur". Traducción castellana: "3 [...] Y si los linderos se hallaren en las tercias que tienen los romanos, entren entonces los godos en el terreno de los huéspedes y lleven el lindero al sitio en que se había señalado. 4. Entonces el juez haga prestar juramento a las personas que encuentre más fidedignas de que indicaron el lindero sin engaño alguno. 5. Nadie fije un nuevo lindero sin el consorte de la otra parte o sin un vecino inspector. 6. Si un hombre libre lo hiciere, sufre la pena que se contiene en las leyes para el invasor de lo ajeno. 7. Si lo cometiera un siervo sin conocimiento del amo, reciba expuesto al público doscientos azotes, y no tenga el dueño más perjuicio por ello". 
indicado en el número anterior. El número 6 prohíbe revisar los juicios fallados durante el reinado de Teodorico I. Y el número 7 ordena remitir al rey los litigios con dos sentencias a fin de que sea el monarca quien determine cuál de ellas ha sido emitida conforme a la ley ${ }^{79}$.

Ninguna de estas disposiciones dice relación con el contenido de las Leyes Teodoricianas y ello no hace sino reforzar la idea de que su inclusión en el Código de Eurico correspondió a un esfuerzo por preservar una legislación que ya había rendido sus frutos. En su palingenesia, el profesor d'Ors, estima, en lo relativo al libro "De divisionibus" que, dado que Eurico recogió las leyes de su padre y hermano y las modificó dándoles un carácter más general, aquél contendría normas sobre la división de las tierras entre copropietarios más allá de las sortes originales. Lo que se habría mantenido en el Código de Leovigildo y en la sección de leges antiquas del Liber ${ }^{80}$. Algunos, tomando como base algunas referencias contenidas en el Liber, provenientes del Código de Leovigildo, han creído que en los territorios de Hispania se respetó el sistema de reparto de dos tercios para los godos y uno para los romanos. Sin embargo, estudios más recientes advierten que en Hispania no se recurrió al sistema de las Leyes Teodoricianas, sino que simplemente los godos pasaron a ocupar las tierras sin que hubiera reparto con los antiguos propietarios, siendo éstos excluidos por completo del dominio de la tierra ${ }^{81}$. Es lo que, por lo demás, afirman las fuentes históricas de Orosio $^{82} \mathrm{e}$

${ }^{79}$ Código de Eurico, CCLXXVII. "2. Similiter de fugitivis qui intra $L$ annis inventi non fuerint, non liceat eos ad servitium revocare. 4. Et alias omnes causas seu bonas seu malas aut etiam criminales quae intra XXX annis definitae non fuerint, vel mancipia quaein contemptione posita fuerant, sine debita quae exacta non fuerint, nullo modo repetantur. 5. Et si quid post hunc XXX annorum numerum causam movere temptaverit, iste numerus ei resistat, et libram auri cui rex iusserit coactus exsolvat. 6. Omnes autem causas quae in regno bonae memoriae patris nostri, seu bonae se malae, actae sunt non permittimus penitus conmoveri. 7. De illis vero causis unde duo iuditia proferuntur, nobis iubemus offerri, ut quae cum lege videremus emissa nobis praecipientibus dibeat probari". Traducción castellana: "2. Asimismo no sea lícito revocar a servidumbre a los siervos fugitivos que no fueron hallados en un plazo de cincuenta años. 4 . Y todos los otros litigios, justos o injustos, incluso los penales, que no fueron fallados en el plazo de treinta años, o los esclavos que hubieran sido objeto de reclamación, o de las deudas que no fueron cobradas, de ningún modo sean ya reclamados. 5. Y si alguno intentara mover el litigio transcurrido este plazo de los treinta años, opóngasele este plazo y pague una libra de oro a quien el rey ordenare. 6. No permitimos en absoluto remover los litigios, justos o injustos, que fueron concluidos reinando nuestro padre de digna memoria, más los que los juzgaron rindan sus cuentas a Dios. 7 Ordenamos que se nos refieran aquellos litigios en los que hay dos sentencias, a fin de que deba aprobarse por nuestro mandato aquella que parezca emitida conforme a la ley".

${ }^{80}$ Ver D’Ors, Álvaro, Código de Eurico, cit. (n. 22), pp. 174ss.

${ }^{81}$ Ibíd. En similar sentido se pronuncia Escudero, José Antonio, cit. (n. 55), p. 178.

${ }^{82}$ Ver Orosio, Historiarum adversum, cit. (n. 8). 
Hidacio $^{83}$, al indicar que en los asentamientos en Hispania, se recurrió al sorteo, y no a la división por tercios ${ }^{84}$.

Los asentamientos permanentes de los godos de Tolosa se produjeron en Hispania a partir de las campañas de Teodorico II y especialmente de Eurico. Se ha sostenido que siendo los visigodos un grupo muy minoritario en relación con los hispanorromanos, no existió un gran conflicto sobre la repartición de las tierras. Por el contrario, se sostiene, en base a la prueba arqueológica, que los godos solo ocuparon algunas zonas de Hispania ${ }^{85}$.

Antes de revisar la siguiente fuente, el Liber Iudiciorum, es necesario comentar la forma en que las disposiciones del Código de Eurico pasaron a la parte de Leges Antiquae del Liber. Tradicionalmente se ha explicado esta circunstancia afirmando que gran parte de estas leyes antiguas fueron tomadas por el redactor de Liber provenientes del Código de Leovigildo o Códex Revisus, supuestamente dictado entre 572 y 586. Sería una obra jurídica de Leovigildo (¿?-572-586), para actualizar el antiguo Código de Eurico. La nueva obra habría añadido leyes, suprimido otras y corregido normas que estaban ya en el viejo Código ${ }^{86}$. Más allá de lo que podamos pensar hoy (la polémica sobre la existencia del Código de Leovigildo sigue abierta), lo cierto es que las leyes del Código de Eurico que nos interesan pasaron con modificaciones al Liber ${ }^{87}$.

83 Ver HIDACIO, Chronicon, XVII: "Subversis memorata plagarum grassatione Hispaniae provinciis, barbari ad pacem ineundam, Domino miserante conversi, sorte ad inhabitandum sibi provinciarum dividunt regiones. Gallaeciam Wandali occupant et Suevi, sitam in extremitate Oceani maris occidua. Alani Lusitaniam et Carthaginiensem provincias, et Wandali cognomine Silingi Baeticam sortiuntur. Hispani per civitates et castella residui a plagis, barbarorum per provincias dominantium se subjiciunt servituti". Traducción castellana: "Abatidas las provincias de España por el ataque memorable de las plagas, los bárbaros, convertidos a la idea del establecimiento de la paz por la misericordia del Señor; se dividen por sorteo las regiones de las provincias para habitarlas. Los Vándalos ocupan Galicia y los Suevos el territorio situado en el extremo que da al mar Océano; los Alanos se sortean las provincias Lusitania y Cartaginense y los Vándalos llamados Silingos se reparten la Bética. Los hispanos de las ciudades y de los castillos que habian podido escapar a la plaga de los bárbaros enseñoreados de las provincias, se doblegan a la servidumbre”. Sobre el particular consultar Arce, Javier, Bárbaros, cit. (n. 3), pp. 67ss. y 107.

${ }^{84} \mathrm{Al}$ respecto sostiene el profesor Arce: “Hubo una negociación personal entre propietarios hispanorromanos y visigodos? En este caso ¿cómo iban los hispanorromanos a conceder a los recién llegados la mayor parte de sus tierras y quedarse ellos con la peor parte? Simplemente no sabemos cómo se realizó el proceso de asignación de tierras. Unas veces ocupando espacios vacios o desiertos; otras, llegando a acuerdos con los locales instalándose en el campo o en las ciudades". Ver ARCE, Javier, Esperando, cit. (n. 3), p. 44.

85 Ver de las Heras y Núñez, María de los Ángeles, cit. (n. 24).

${ }^{86}$ Ver IsIdoro, de Sevilla San, Historia de Regibus gothorum, 51. "In legibus quoque ea quae ab Eurico incondite constituta videbantur, correxit, plurimas leges praetermissas adjiciens, plerasque superfluas auferens".

${ }^{87}$ El rastreo de las disposiciones propias del Código de Leovigildo puede hacerse con los fragmentos del Palimpsesto de París y el texto del Líber. Aquí retorna la polémica, pues algunos sostienen que las diferencias son solo errores o correcciones de copia y otros afirman que serían diferencias de mayor importancia. Ver EsCudero, José Antonio, cit. (n. 55), p. 209. 


\section{En el Liber Iudiciorum dictado en 654.}

La disposición fundamental, ley antigua (tomada del Código de Leovigildo o directamente del de Eurico), es: Liber Iudiciorum, X, 1, 8, Antiqua: “De divisione terrarum facta inter Gothum et Romanum. Divisio inter Gotum et Romanum facta de portione terrarum sive silvarum, nulla ratione turbetur, si tamen probatur celebrata divisio, nec de duabus partibus Goti aliquid sibi Romanus praesumat aut vindicet, aut de tertia Romani Gotus sibi aliquid audeat usurpare aut vendicare, nisi quod a nostra forsitan ei fuerit largitate donatum. Sed quod a parentibus, vel a vicinis divisum est, posteritas immutare non temtet. ${ }^{88}$

El texto que comentamos resume el contenido original de las Leyes Teodoricianas. Este reparto, así realizado formalmente, no podía ser impugnado ni por los godos ni por los romanos para reclamar más de lo que les correspondía por aplicación de la fórmula de división. Solo agrega, en una interpolación atribuible con mayor probabilidad al Código de Leovigildo, la excepción de respetar las donaciones regias de tierras que pudieran haber alterado la repartición original. Excepción que no parece haber sido invocada, aunque nuestra documentación al respecto es muy precaria. Y finalizaba la norma indicando que las reparticiones hechas en el pasado por los padres y vecinos no debían tampoco ser revisadas. El fragmento ha sido preservado dentro del Libro X "De divisionibus et temporibus atque limitivus", título I "De divisionibus et territ ad placitum datis" del Liber Iudiciorum y de su versión romance tardía, el Fuero Juzgo ${ }^{89}$, denominaciones generales que reservan el régimen de sortes a las leyes 8,9 y 16 . En ello se demuestra que la intención del legislador de 654 fue conservar este viejo sistema de reparto de tierras, tendiendo a preservar las divisiones hechas y evitar juicios al respecto pero integrándolo dentro de un título más amplio relativo a todo tipo de división de tierras y copropiedad.

Lo demuestra igualmente el precepto que sigue al citado: Liber Iudiciorum, X, 1, 9, Antiqua: "De silvis inter Gotum et Romanum indivisis relictis. De silvis, quae indivise forsitan residerunt, sive Gotus sive Romanus sibi eas adsumserit, fecerit fortasse culturas, statuimus, ut, si adhuc silva superest, unde paris meriti terra eius, cui debetur, portioni debeat conpensari, silvam accipere non recuset. Si autem paris meriti, que compensetur, silva non fuerit, quod ad culturam excisum est dividatur" ${ }^{90}$.

${ }^{88}$ El texto original latino ha sido tomado de RECESVINTO, Liber Iudiciorum (Madrid, Boletín Oficial del Estado, 2015). Traducción castellana: "De la partición de tierras hecha entre godos y romanos. La partición de las porciones de tierras o de bosques hecha entre godos y romanos, que no se cuestione por ningún motivo, si asimismo se demuestra que la partición fue formalizada, y que el romano no se atribuya ni reclame nada de las dos terceras partes del godo ni el godo pretenda usurpar ni reclamar nada de la tercera parte del romano, salvo que quizá le haya sido concedida por nuestra generosidad. Pero aquello que fue repartido por los padres y los vecinos, que la posteridad no lo intente cambiar".

${ }^{89}$ No consideramos acá la versión romanceada del Fuero Juzgo por corresponder a un tiempo y circunstancias enteramente diversas. La versión española que hemos consignado es la que se desprende del texto original del Liber.

${ }_{90}$ Traducción castellana: "De los bosques dejados sin repartir entre godos y romanos.

De los bosques que tal vez quedaron sin repartir, tanto si se los atribuyere un godo como un romano, y alli hiciere cultivos, establecemos que, si aún queda bosque para que se pueda compensar 
En este caso se trataba de los bosques poseídos proindiviso por los godos y romanos. Con los bosques no se produjo la conocida división en sortes y tercias como en el caso de las tierras. El precepto se basa en la idea de compensar al que no hubiese hecho uso del mismo dándole en calidad de reparación una porción del bosque no usada equivalente a la ocupada por el otro consorte y en caso de no haberla, se ordenaba compensarle dividiendo la tierra resultante de la tala del bosque para dedicarla a la labranza. d'Ors afirma que este sistema era supletorio de lo que acordaran las partes y que la distribución proindiviso debía guardar alguna relación con la distribución de las tierras dos a uno y no necesariamente ser a medias ${ }^{11}$.

En el resto del título I se contienen otras normas relativas a la partición de viñas, edificios, la validez de la división de las tierras por el siervo que actuaba sin permiso del dueño y tierras arrendadas.

Además debemos recordar la ya citada Ley antigua 10, 1, 16: "Iudices singularum civitatum, vilici adque prepositi tertias Romanorum ab illis qui occupatas tenent, auferant et Romanis sua exactione sine aliqua dilatione restituant, ut nibil fisco debeat deperire; si tatem eos quinquaginta annorum numerus aut tempus non excluserit", que d'Ors ha identificado acertadamente, como una Ley Teodoriciana, aunque con una interpolación de Eurico en su parte final. El precepto ordena que los jueces debían restituir sin dilación a sus propietarios romanos originales las porciones de tierra abusivamente ocupadas por los godos. Lo que implica que el precepto fue redactado en tiempos en que las reparticiones de tierras se estaban efectuando o en el tiempo inmediato, a fin de evitar los abusos y dar a los romanos el derecho de obtener amparo judicial frente a cualquier tipo de injusticia. La disposición se cierra ordenando no revisar este tipo de repartos si hubiesen pasado más de 50 años luego de realizados, lo que induce a pensar en que esta prohibición final fue obra de Eurico al considerar la necesidad de dar por concluido el problema de la repartición de tierras ${ }^{92}$.

Finalmente la disposición que encabeza el título II (De quinquagenarii et tricennalis temporis intentione) del mismo Libro X del Liber, confirma la norma anterior: "Sortes gotice et tertia Romanorum, que intra L annos non fuerint revocate, nullo modo repetantur" 93 . En ella se reitera que las reclamaciones sobre reparto de tierras tenían un plazo especial de prescripción (50 años) mientras que las demás materias se regían por el plazo ordinario (de 30), en atención a la importancia que se atribuía al dominio de la tierra.

Estas dos últimas leyes antiguas vienen a demostrar que los reyes godos legislaban para la totalidad de la población de su reino, pues no se podría comprender la

con tierra de la misma cualidad la porción de aquél a quien es debida, éste no rehúse aceptar el bosque. Pero si no hubiese un bosque de la misma cualidad con que pueda ser compensado, que le sea repartido aquello que se haya cortado para cultivos".

91 Ver D’Ors, Álvaro, Código de Eurico, cit. (n. 22), p. 177.

92 Ibíd., p. 179.

93 Título II (De la objeción de los periodos de cincuenta y treinta años), 1. Traducción castellana: "Las tierras asignadas a los Godos y la tercera concedida a los Romanos, si no hubieren sido revocadas en el plazo de cincuenta años, que no sean de ninguna manera objeto de reclamación". 
disposición al concebirla solo como destinada a los godos. Sería entonces absurdo permitir que el propietario romano tuviera acceso a los tribunales para exigir "sine aliqua dilatione" la restitución de su parte del terreno indebidamente ocupada.

Es importante que el Liber haya mantenido las antiguas las Leyes Teodoricianas. Hacia mediados del siglo VII el problema de la repartición de las tierras ya había sido suficientemente resuelto por dos siglos de políticas al respecto, pero en la mente del redactor del Liber el asunto continuaba siendo suficientemente importante como para que se reprodujeran las reglas citadas. Seguramente la labor de los jueces, las siempre complejas relaciones entre godos e hispanorromanos, ahora unificados en un solo pueblo, pero con importantes diferencias materiales y sociales todavía, constituían un sustrato suficiente para que el Liber, cruce cultural de derecho, teología y literatura cristianas ${ }^{94}$, no solo incluyera las normas indicadas, sino que se hiciera cargo de eventuales conflictos como las demandas por las divisiones.

\section{IMPORTANCiA DE Las Leyes TeOdoricianas}

\section{En su época.}

Las Leyes Teodoricianas fueron, en su tiempo, un notable ejemplo de la preocupación de los líderes godos por regular materias que podrían haber originado un sinfín de problemas de convivencia. El que los reyes Teodorico I y II hayan dictado estas leyes escritas y con validez territorial demuestra su alto grado de compromiso con la cultura romana. Las leyes consagraron en la práctica un régimen similar al de la vieja hospitalitas romana pero adecuado a nueva realidad. Es una muestra de civilización alejada de la b a r b a r i e que el desconocimiento atribuye a los godos. De haberse procedido como bárbaros, los dos Teodoricos no se habrían molestado en dictar estas leyes, sino que habrían autorizado a su pueblo a tomar por la fuerza todas las tierras y bienes que hubiesen querido y podido ocupar.

Los romanos, resignados al nuevo panorama político y social, debieron ver con alivio como los nuevos señores dictaban leyes escritas y consagraban fórmulas de reparto similares a las que ya conocían. Asimismo debieron valorar los derechos que las leyes les otorgaban, tanto en la partición misma de las tierras, al darles el derecho de escoger la tercera parte de las tierras que conservarían, como la facultad de reclamar ante los jueces en caso de abuso en la repartición o en la ocupación posterior. De no haber sido por las Leyes Teodoricianas, los problemas de relación entre ambos grupos humanos podrían haber devenido en un conflicto permanente, con el temor del uso de la fuerza por cualquiera de los dos sectores.

\section{Para nosotros.}

El significado de esta legislación para nosotros es doble. Por una parte aclara la forma en que el reino visigodo de Tolosa fue organizándose en forma paralela a la etapa final del Imperio Romano. Dice mucho de un pueblo y de sus líderes,

${ }^{4}$ Ver Petit, Carlos, Derecho visigodo del siglo VII. Un ensayo de sintesis e interpretación, en VV.AA., Hispania Gothorum. San Ildefonso y el reino visigodo de Toledo. Catálogo de la exposición (23 enero-30 de junio 2007) (Toledo, Empresa pública Don Quijote 2005 S.A., 2007), pp. 1-15. 
el que un tema de tanta importancia como el régimen de asentamiento sobre las tierras haya sido resuelto por la vía del derecho. Y de uno muy influido por los modelos romanos ${ }^{95}$.

Pero la faceta más interesante de las Leyes Teodoricianas es la de dilucidar cuál fue el principio de vigencia que conocieron los legisladores godos de ese tiempo y de los posteriores. Entre la personalidad de las costumbres bárbaras y la territorialidad romana, los visigodos optaron por la segunda.

¿Cómo podemos afirmar esto tan categóricamente? Revisemos las diversas alternativas:

La supuesta personalidad del Derecho godo. Conviene recordar aquí que la tesis tradicional sostuvo que el derecho visigodo, en los tiempos del Código de Eurico (y con mayor razón en el de nuestras Leyes Teodoricianas), se basó en el principio de la personalidad jurídica, es decir, que habría sido aplicado solamente a los godos. La siguiente gran compilación visigoda, el Breviario de Alarico o Lex romana visigothorum se habría aplicado a la población romana. Luego, en tiempos del reino toledano, el Código de Leovigildo o Códex revisus habría sido redactado exclusivamente para la población visigoda reemplazando del todo al Código de Eurico. Y solo con la dictación del Liber Iudiciorum en 654 se habría producido la adopción del principio jurídico territorial al aplicarse el Líber a la totalidad de la población ${ }^{96}$. Pero no es esta la tesis que hoy comparte la mayor parte de la historiografía.

La tesis de don Alfonso García-Gallo, sobre la territorialidad del derecho visigodo, es ampliamente conocida. Y mantiene su influencia aun con las matizaciones realizadas más tarde ${ }^{97}$. Podemos sintetizarla de la manera siguiente ${ }^{98}$ :

Basándose en la evidencia histórica de que disponemos, en los propios textos jurídicos y en las instituciones que contienen, el profesor García-Gallo concluyó que el derecho visigodo fue siempre de aplicación territorial. Los sucesivos cuerpos legales dictados fueron aplicados territorialmente y cada nueva fuente mayor derogó a la anterior. Esta última parte de la tesis de García-Gallo fue discutida por el profesor D'Ors y más tarde revisada por el primero, indicando que no necesariamente los cuerpos legislativos visigodos derogaron a los anteriores ${ }^{99}$. En primer lugar sostiene que carece de sentido plantear que unos cuerpos legislativos tan romanizados como el Código de Eurico y el de Leovigildo, se hayan aplicado sólo a los godos. Además como Eurico promulgó su Código, en virtud de la autoridad del Prefecto de las Galias, que había asumido, es lógico que se aplicara para todo el territorio aludido. Asimismo sería contradictorio que el que

${ }^{95}$ Ver Alvarado Planas, Javier, El problema del germanismo en el derecho español, siglos V-XI (Madrid, Marcial Pons ediciones jurídicas y sociales S.A., 1997), pp. 17ss.

${ }_{96}$ Ver ejemplo de esta tesis en Thompson, E. A., Los godos, cit. (n. 18), pp. 132ss. y EscuDERO, José Antonio, cit. (n. 55), p. 213.

${ }_{97}$ Un completo resumen del estado de la cuestión en Alvarado Planas, Javier, El problema, cit. (n. 95), pp. 15-31.

${ }_{98}$ Ver García-Gallo, Alfonso, Nacionalidad y territorialidad del Derecho en la época visigoda, en AHDE., 13 (Madrid, 1936-1941), pp. 168-264.

99 Ver Merello Arecco, Ítalo, Historia del Derecho ${ }^{2}$ (Valparaíso, Ediciones Universitarias de Valparaíso, 1983), I, p. 108. 
unos cuerpos jurídicos de tan alta calidad, que recogían la totalidad de un sistema jurídico vigente, fueran pensados para regir tan escaso tiempo. Finalmente sostiene que es absurdo pensar que los reyes godos habrían consumido tantos esfuerzos por dictar una legislación aplicable a una cantidad tan pequeña de gentes como sus hermanos de raza que eran una minoría dentro de una inmensa población galo e hispanorromana. Un ejemplo es la Ley de Teudis (¿?-531-548) que expresamente se dictó en 546 "per universos populos ${ }^{100 " . ~}$

Nuestra interpretación. Luego de todo lo que hemos analizado, nos pronunciamos por la tesis del profesor García Gallo, pero sin perjuicio de compartir sus argumentaciones, podemos añadir que consideramos que el derecho visigodo siempre fue territorial debido, precisamente, a la existencia de las Leyes Teodoricianas.

No reconocer en ellas un ejemplo perfecto de territorialidad sería negar evidencia histórica y jurídica. La única forma en que la legislación estudiada pudiere aplicarse es de manera territorial, con validez directa e inmediata sobre toda la población y nunca sobre el principio personal, solo para los godos ${ }^{101}$. De lo contrario, ¿cómo podría explicarse el que el propietario romano original de las tierras tuviere derecho a escoger y conservar su tercia? Habría sido un absurdo. Y más aún, si no el propietario romano tenía asimismo el derecho de recurrir a los tribunales en caso de desconocerse sus derechos.

Más aún, los reyes godos concedieron a los romanos un plazo especial para poder reclamar, de 50 años, plazo mayor al general de prescripción de 30 años. Ello nos permite concluir sin duda, que la legislación teodoriciana fue una manifestación de la cultura romana adquirida por los visigodos y compartiendo con ella su principio de vigencia, se aplicó a toda la población. Por lo demás, resulta poco razonable pensar que los reyes godos, que buscaban siempre formas de consolidar su poder, dictasen estas leyes que les conferían legitimidad, sólo para los visigodos, dejando de lado el gobierno de sus súbditos galos e hispanorromanos que eran la inmensa mayoría de la población. Finalmente, siendo la territorialidad uno de los más distintivos atributos del derecho romano, al imitar, recompilar y preservar este derecho, las leyes visigodas no hicieron más que adoptar este principio.

\section{CONCLUSIONES}

A diferencia de los demás pueblos germanos, los visigodos tuvieron un largo contacto con la cultura romana. Dicha relación nos permite explicar que los

100 Traducción castellana: "para todas las personas". Ver García-Gallo, Alfonso, Nacionalidad y territorialidad, cit. (n. 98), p. 219.

${ }^{101}$ En contra el profesor Alvarado Planas sostiene que las leyes sobre repartición de las tierras establecieron un sistema que "es compatible con un régimen de personalidad del Derecho en el que a la hora de regular la distribución de tierras entre gentes de dos razas sería inevitable referirse a cuestiones mixtas". Estimamos que su afirmación contiene un elemento ilógico, esto es aceptar unas leyes personalistas pero aplicadas a toda la población que vive en un territorio, lo que implica sacrificar la esencia del mismo régimen, el que las leyes se aplicaran separadamente a los grupos para los que se dictaron. Ver Alvarado Planas, Javier, El problema, cit. (n. 95), p. 29. 
visigodos, particularmente sus líderes, estuvieran intensamente romanizados al tiempo de surgir la legislación que hemos estudiado.

Las fuentes históricas disponibles son concordantes en el sentido de que desde los acuerdos entre Walia y Honorio de 416 y 418, los visigodos pasaron a constituir un elemento de gran importancia dentro de la política imperial romana y para la misma población romana, que comenzó a verlos ya no como simples invasores, sino como un elemento de legitimidad, estabilidad, y fuente de posible auxilio frente a otros pueblos bárbaros.

Fruto de dicha nueva legitimidad fue la legislación que dictaron para resolver los acuciantes problemas surgidos debido a su asentamiento en los territorios en que vivía la población romana.

La historiografía y la arqueología están contestes en que los visigodos representaron una muy pequeña minoría, que aunque dominante en teoría, debía compartir su tierra con una inmensa mayoría de población romana, con una aristocracia terrateniente que mantuvo su influencia y que hacía impensable que el reino godo pudiera gobernarse solamente con los líderes germanos.

Las Leyes Teodoricianas fueron el primer caso de legislación escrita que dictaron los gobernantes visigodos. Con ellas, el derecho godo se apartó de la costumbre personal y de la oralidad y se inscribió para siempre en la escritura y la territorialidad.

Las leyes de Teodorico I y II permitieron repartir los territorios mediante un procedimiento sencillo de aplicar, que se originaba en la antigua hospitalitas romana. Tan eficientes fueron, que en tiempos del Código de Eurico, la división de las tierras ya había concluido.

Estas leyes tuvieron un carácter especial, supletorio del derecho romano pero no invalidaron las leyes romanas en las demás materias que conocemos. Las Leyes Teodoricianas, reproducidas por Eurico en su Código y mucho más tarde en el Liber Iudiciorum, permanecieron en vigencia a lo largo de toda la historia visigoda, tanto en el reino tolosano como en el toledano español.

Sin embargo, el valor jurídico más grande de esta legislación, es que prueba indubitablemente, más allá de las argumentaciones jurídico-culturales de García Gallo y D'Ors, que el derecho visigodo fue siempre territorial. Ello explica la promulgación de unas leyes que concedían derechos de optar a tierras a godos y romanos, aplicables a todos por igual.

\section{Bibliografía General}

Alvarado Planas, Javier, El problema del germanismo en el derecho español, siglos V-XI (Madrid, Marcial Pons ediciones jurídicas y sociales S.A., 1997).

Alvarado Planas, Javier, et al., Manual de Historia del Derecho y de las Instituciones (Madrid, Editorial Sanz y Torres S. L., 2006).

Alvarado Planas, Javier, Montes Salguero, Jorge J., Pérez Márcos, Regina María, SÁnchez GonzÁlez, María Dolores del Mar, Practicum, textos comentados de Historia del Derecho y de las Instituciones adaptados al programa de la Uned (Madrid, Editorial Universitaria Ramón Areces, 2005). 
ARCE, Javier, Bárbaros y romanos en Hispania (400-507 A.D.) (2005, primera reimpresión de la segunda edición, Madrid, Marcial Pons Historia, 2011).

ArCe, Javier, Esperando a los árabes. Los visigodos en Hispania (507-711) (Madrid, Marcial Pons Historia, 2011).

ButLer, Alban, Vidas de los Santos de Butler (1954, traducción castellana de Wilfredo Guinea, S. J., México, Orozco y Berra, 1965), III.

Castellanos, Santiago, En el final de Roma. (ca. 455-480) (Madrid, Marcial Pons Historia, 2013).

Castellanos, Santiago, Los godos y la cruz. Recaredo y la unidad de Spania (Madrid, Alianza Editorial, 2007).

Cebrián, Juan Antonio, La aventura de los Godos (Madrid, Editorial la Esfera de los Libros, 2002).

Chaix de Lavarène, Louis Antoine C., Saint Sidoine Apollinaire et son siécle (Clermont-Ferrand, Ferdinand Thibaud Imprimeur Libraire, 1866).

Dalton, O. M. The letters of Sidonius (Oxford, The Clarendon Press, 1915), I-II.

De la Peña y Portillo, Dionisio, De la ley de los visigodos (Madrid, Imprenta de la Esperanza, 1858).

De las Heras y NúNEz, María de los Ángeles, Las instituciones visigodas, en http:// www.vallenajerilla.com/berceo/heras/institucionesvisigodas.htm

Díaz, Pablo C., Rey y Poder en la monarquía visigoda, en Iberia, 1 (Logroño, 1998).

D’Ors, Álvaro, El Código de Eurico, Edición, Palingenesia, Indices² (Madrid, Boletín Oficial del Estado, 2014).

EPISCOPOlOGIO AstURICENSE: http://bibliotecadigital.jcyl.es/i18n/catalogo imagenes/ grupo.cmd?path $=1006419$ \&interno $=S \&$ posicion $=262 \&$ presentacion=pagina

Escudero, José Antonio, Curso de Historia del Derecho, Fuentes e Instituciones político administrativas ${ }^{2}$ (Madrid, Talleres de Gráficas Solana, 1995).

Ferril, Arther, La caída del Imperio Romano, las causas militares ${ }^{3}$ (1986, traducción castellana de Pilar González Bermejo, México, Editorial EDAF, 1998).

Gacto Fernández, Enrique, Alejandre García, Juan Antonio y García Marín, José María, Manual de Historia del Derecho (Temas y antología de textos) (Madrid, Editorial Dykinson, 2013).

García-Gallo, Alfonso, El origen y la evolución del derecho, Manual de Historia del Derecho Español (Madrid, Artes Gráficas y Ediciones S.A., 1977), I.

GarCía-Gallo, Alfonso, Nacionalidad y territorialidad del Derecho en la época visigoda, en $A H D E ., 13$ (Madrid, 1936-1941).

GarCía-Gallo, Alfonso, Notas sobre el reparto de tierras entre visigodos y romanos, en Hispania, 4 (Madrid, 1941).

García GonzÁlez, Juan, Consideraciones sobre la fecha del Código de Eurico, en AHDE., 26 (Madrid, 1956).

Gaupp, E. Th., Die Germanischen Ansiedlungen und Landttheilungen in den Provinzen des römischen Westreiches in ihrer völkerrechtlichen Eigenthümlichkeit und mit Rücksicht auf verwandte Erscneinungen der alten Welt und des späteren Mittelalters dargestellt (Breslau, 1844).

Gesino, Marta, El libro séptimo de las historias contra los paganos de Paulo Orosio, en Anales de Historia Antigua y Medieval, 1959-1960 (Buenos Aires, 1961).

Girotti, Beatrice, Spunti per la continuità tra Olimpiodoro di Tebe e Prisco di Panion, en Historia: Zeitschrift für Alte Geschichte, 54 (Erfurt, 2005) III. 
GOFFART, Walter A., Barbarians and Romans, A.D. 418-584: The Techniques of Accommodation (Chichester, Princeton University Press, 1980).

Gregoire, J. F. y collombet F. L., Oeuvres de C. Sollius Apollinaris Sidonius, Traduites en Francais avec le Texte en Regard et des Notes (París, Broché, 1836) I y II.

Heather, Peter, La caída del Imperio Romano² (2005, traducción castellana de Tomás Fernández Aúz y Beatriz Eguibar, Barcelona, Editorial Crítica, 2008).

IDATIUS AqUAEFLAVIENSIS EPISCOPUS-CHRONICUM en http://www.thelatinlibrary.com/ hydatius chronicon.html

Jiménez Garnica, Ana María, Nuevas Gentes, Nuevo Imperio: Los Godos y Occidente en el Siglo V (Madrid, Editorial UNED, 2010).

Jones, A.H.M., Martindale, J.R. y MorRIs, J. Prosopography of the Later Roman Empire (Cambridge, Cambridge University Press, 1971-1992) II.

Jones, Terry y EREIRA, Alan, Roma y los bárbaros, una historia alternativa (2006, traducción castellana de Tomás Fernández Aúz y Beatriz Eguibar, Barcelona, Editorial Crítica, 2008).

LardizÁbal y Uribe, Manuel de, Discurso, en Fuero Juzgo por la Real Academia Española, 1815 (Madrid, Boletín Oficial del Estado, 2015).

Le Goff, Jacques, La civilización del occidente medieval (1982, traducción castellana de Godofredo González, Barcelona, Ediciones Paidós Ibérica. S.A., 1999).

Madden, Marie Regina, Political theory and law in medieval Spain (Clark, The Lawbook Exchange Ltd., 2005).

Marín Riveros, José, Textos históricos. Del Imperio Romano hasta el siglo VIII (Santiago, RIL Editores, 2003).

Mathisen Ralph W. y Sivan, Hagith S. Forging a new identity: The kingdom of Toulouse and the frontiers of visigothic Aquitania (418-507), en FERREIRO, Alberto (editor), The Visigoths: Studies in Culture and Society (Koninklijke, Brill, 1999).

MatTHEws, J. F., Olympiodorus of Thebes and the history of the west (A.D. 407-425), en The Journal of Roman Studies, 60 (London, 1970).

Merello Arecco, Îtalo, Historia del Derecho ${ }^{2}$ (Valparaíso, Ediciones universitarias de Valparaíso, 1983), I.

Montiel, Isidro A., Cuadro Sinóptico del Código de Eurico, en El Derecho, Periódico de jurisprudencia y legislación, I (México, 1868), V.

Morán Martín, Remedios, Materiales para un curso de Historia del Derecho español (Madrid, UNED, 2010), I.

OrLANDis, José, Historia del Reino Visigodo Español (Madrid, Editorial Rialp, 2006).

OrLandis, José y Ramos-Lisson, Domingo, Historia de los Concilios de la España romana y visigoda (1981, traducción castellana de ellos mismos, Pamplona, EUNSA, 1986).

Ortiz de Zárate, Ramón, Análisis histórico-critico de la legislación española (Vitoria, Imprenta y litografía de Egaña y Cía., 1844), I.

PETIT, Carlos, Derecho visigodo del siglo VII. Un ensayo de sintesis e interpretación, en Vv.AA., Hispania Gothorum. San Ildefonso y el reino visigodo de Toledo. Catálogo de la exposición (23 enero-30 de junio 2007) (Toledo, Empresa pública Don Quijote 2005 S.A., 2007).

Rosen, William, El fin del Imperio Romano, la primera gran peste de la era global (2007, traducción castellana de Marita Osés, Barcelona, PAIDÓS, 2008).

Saranyana, Josep-Ignasi y Tejero, Eloy (eds.), Hispania Christiana, estudios en honor del prof. Dr. José Orlandis Rovira en su septuagésimo aniversario (Pamplona, EUNSA, 1988). 
SAITTA, Armando, Guía critica de la historia medieval (1981, primera reimpresión, traducción castellana de Stella Mastrangelo, México, Fondo de cultura económica, 1996).

Sayas Abengochea, Juan José, Historia antigua de la peninsula ibérica (Madrid, Ediciones UNED, 2014).

Sidonius Apollinaris: http://www.sidoniusapollinaris.nl

Stevens, C. E., Sidonius Apollinaris and his Age (Oxford, Clarendon Press, 1933).

TERTULIAN.ORG, disponible en http://www.tertullian.org/fathers/ \#sidonius_apollinaris The Latin Library, disponible en http://www.thelatinlibrary.com/sidonius.html

Thompson, E. A., Los godos en España (1969, traducción castellana de Javier Faci, Madrid, Alianza Editorial Historia, 2007).

Thompson, E. A., Olympiodorus of Thebes, en The Classical Quarterly, 38 (Cambridge, 1944) $1 / 2$, pp. 43-52.

TORRes López, Manuel, Las invasiones y los reinos germánicos de España, en MENÉNDEZ PIDAl, Ramón (editor), Historia de España (Madrid, Espasa Calpe, 1954), III.

Torres Rodríguez, Casimiro, Paulo Orosio. Su vida y sus obras (La Coruña, Fundación Pedro Barrie de la Maza Conde de Fenosa, 1985).

UReÑa y SMENJaUd, Ramón, La legislación gótico-hispana (leges antiquiores-Liber Iudiciorum). Estudio crítico (Pamplona, Urgoiti Editores, 2003).

Valverde Castro, María R., Ideología, simbolismo y ejercicio del poder real en la monarquía visigoda; un proceso de cambio (Salamanca, Ediciones Universidad de Salamanca, 2000).

Zeumer, Karl, Historia de la legislación visigoda (Barcelona, Editorial Universidad de Barcelona, 1944). 
